\title{
FUENTES DE RIQUEZA Y PROMOCIÓN SOCIAL DE LOS NEGOTIANTES SALSARII BÉTICOS EN EL ALTO IMPERIO ROMANO. UNA APROXIMACIÓN DIACRÓNICA
}

\author{
SOURCES OF WEALTH AND SOCIAL PROMOTION \\ OF THE NEGOTIANTES SALSARII FROM BAETICA \\ DURING THE EARLY ROMAN EMPIRE. \\ A DIACHRONIC APPROACH
}

\author{
ENRIQUE GARCÍA VARGAS ${ }^{1}$ \\ Universidad de Sevilla \\ JULIO MARTÍNEZ MAGANTO \\ Universidad Autónoma de Madrid
}

\section{RESUMEN}

Planteamos un estudio centrado en los mecanismos de promoción socio-económica que experimentaron los comerciantes de salazón en la Bética romana durante el Alto Imperio, al margen de su propio origen social. Los testimonios de la epigrafía (lapidaria y anfórica) constituyen la base fundamental sobre la que asentar las evidencias de su paulatina aproximación a las elites sociales de Roma, en perjuicio de sus propias comunidades de origen.

\section{SUMMARY}

In this paper, we propose a study about social and economic promotion mechanisms among salted fish traders in Roman Baetica during the Early Empire, independently of their social origin. Items obtained by epigraphy (either stone tablets or amphorae) are the fundamental basis for evidence as to their gradual moving towards social elites from Rome, even to the detriment of their own original communities.

PALABRAS CLAVE: Comercio romano, economía romana, navicularii, negotiatores, mercatores, salazones, ánforas, evergetismo, Baetica.

KEY WORDS: Roman trade, Roman economy, navicularii, negotiatores, mercatores, salted fish, amphorae, evergetism, Baetica.

\footnotetext{
${ }^{1}$ Correo electrónico: egarcia@us.es

${ }^{2}$ Correo electrónico: julio.martinez@uam.es
}

\section{INTRODUCCIÓN}

En un reciente trabajo, L. Lagóstena $(2004,218)$ constataba que la comparación exhaustiva entre el registro epigráfico de las ánforas salsarias béticas y la epigrafía «mayor» no se ha realizado aún en toda su complejidad. El propio L. Lagóstena (2001, 294295 y 301-305), R. Étienne y F. Mayet (1998; 2002) y, últimamente, C. Morales Muñoz (2005) y R. Rovira Guardiola (2007), han puesto, siempre con buen criterio, las bases de esta tarea que aún debe avanzar más por un camino apenas emprendido. Obviamente, sería posible mejorar las expectativas si logramos establecer un análisis sistemático de la estructura «normativa» de los tituli picti sobre ánforas salsarias (Martínez Maganto 2000; Lagóstena 20023), a la vez que se arbitran cauces de comparación con la epigrafía lapidaria.

Sin embargo, nuestra intención aquí no es ensayar un detenido cotejo entre los nombres de negotiatores y mercatores citados en las ánforas salsarias y sus homónimos en la epigrafía lapidaria (o en el resto del instrumentum domesticum), sino más bien obtener una amplia visión que abarque aspectos jurídicos, económicos y cronológicos, superando así el marco habitual de simples paralelos entre series epigráficas. Por tanto, conviene explicitar los parámetros en los que vamos a desarrollar esta tarea, 
empezando por establecer unas breves aclaraciones iniciales sobre estos ámbitos citados, siendo conscientes de la complejidad que implica una interpretación económica como la que aquí proponemos. Por aspectos jurídicos entendemos no sólo cuestiones técnicas o estrictamente legales del Derecho, tema de enorme amplitud (Biscardi 1982), sino más bien el conjunto de relaciones que los comerciantes establecen entre sí y/o con las instituciones públicas o privadas. Estas últimas son complejas y mutables en el tiempo y cuando aparecen reguladas por el Derecho evidencian el interés de la Administración por incentivar la participación de los privados en el abastecimiento del Estado.

Por su parte, los aspectos económicos no se refieren a una simple delimitación del cálculo racional de beneficios, sino que reflejan las complejas relaciones existentes dentro de la esfera económica; van, por tanto, más allá del simple beneficio, al implicar actos y actitudes concretas encaminadas a la obtención de prestigio o promoción social. Éstos se expresan casi siempre mediante fórmulas evergéticas a cargo de individuos de variada condición que, junto a las redes de amistad, influencia y clientelismo, constituyen algunos de los mecanismos que contribuyen a movilizar la riqueza y animar los mercados.

Finalmente, los aspectos cronológicos merecen una especial atención, ya que delimitan el marco en el que se insertan los dos ámbitos anteriores y posibilitan considerar la industria salazonera sudhispana desde una perspectiva diacrónica, inmersa en un proceso general de cambios, sean éstos sociales, económicos o jurídicos. Sólo podemos analizar adecuadamente tales cambios si trabajamos sobre una secuencia cronológica bien trabada.

LIBRES Y LIBERTOS: LA CONSOLIDACIÓN DE LOS NEGOTIANTES SALSARII BÉTICOS EN EL ORDEN SOCIAL DEL ALTO IMPERIO ROMANO A PARTIR DEL SIGLO II D. C. (Figs. 1-4)

Permítasenos comenzar in media res, en el siglo II d. C., un momento especialmente interesante en el que se asientan los numerosos cambios que se han ido fraguando desde época julio-claudia. De este modo, podemos obtener una visión ya consolidada del papel de los negotiantes para, posteriormente, retrotraernos a la situación de origen en el siguiente apartado. Esta estrategia expositiva posibilita comprender mejor qué ha cambiado en relación con los tiempos anteriores. Por desgracia, contamos con es- casos testimonios epigráficos de esta época referidos a los comerciantes de salazones béticos, aunque quizá sean suficientes para mostrar los cambios introducidos en las estructuras del comercio en esta nueva época, así como su paulatino afianzamiento. Los testimonios disponibles ${ }^{3}$ muestran situaciones socioeconómicas diversas, lo que seguramente refleja la existencia de grupos diferentes de negociantes empeñados en un mismo negocio, aunque trabajando en el seno de un entorno económico dinámico y sumamente complejo.

La primera de estas situaciones viene definida por una interesante inscripción hallada en Málaga (CIL II, 1971) y fechada en torno al año 144 d. C. en la que se recoge un hecho singular. Según el texto, los ciudadanos de Malaca habían reunido dinero para elevar una estatua en honor de Valeria Lucilla, esposa de Marcus Valerius Proculus, quien por entonces era prefecto de Egipto y lo había sido antes de la Annona (142-144 d. C.). Sin embargo, un individuo de nombre P. Clodius Athenio devolvió el dinero a la ciudad y afrontó personalmente el gasto de erección de la imagen de esta mujer. El hecho no tendría mayor relevancia para nuestros propósitos si no fuera porque P. Clodius Athenio aparece en otra inscripción, esta vez de Roma (CIL VI, 9677), como negotians salsarius y quinquennalis corporis negotiantium Malacitanorum.

Sin duda, el objetivo perseguido por Athenio era la obtención de prestigio ante sus conciudadanos ahorrando dinero público y fomentando su relación cercana con Valerius Proculus, el antiguo prefecto de la Annona, y su mujer. Sin embargo, una interpretación más detenida de este hecho revela intenciones no tan desinteresadas, ya que, además del prestigio, la relación de Athenio con Proculus podía llegar a reportarle interesantes ventajas fiscales no sólo a él mismo, sino también al resto de los negotiatores Malacitani e incluso al propio municipio en que éstos estaban radicados.

Siguiendo con esta estrecha relación entre los municipios y los comerciantes el caso de L. Iunius Nothus de Singilia Barba (Cerro del Castillón, Antequera) resulta muy interesante ya que nos permite descender un peldaño en la jerarquía de redes de clientelismo. Este individuo, con una posición social

\footnotetext{
${ }^{3}$ Con ánimo de hacer más dinámica la lectura de este complejo panorama se han definido unas tablas-resumen que recogen referencias de todos los individuos citados en el texto, tanto en Baetica como fuera de esta área (Figs. 1 y 2). Asimismo, siguiendo idéntico criterio, se han confeccionado unos mapas que facilitan la visión espacial y la ubicación de los diferentes topónimos aludidos en el texto (Figs. 3 y 4).
} 
FUENTES DE RIQUEZA ... DE LOS NEGOTIANTES SALSARII BÉTICOS...

RELACIÓN DE TOPÓNIMOS Y ANTROPÓNIMOS CITADOS EN EL TEXTO

Y SUS POSIBLES RELACIONES [ÁREA DE LA BAETICA]

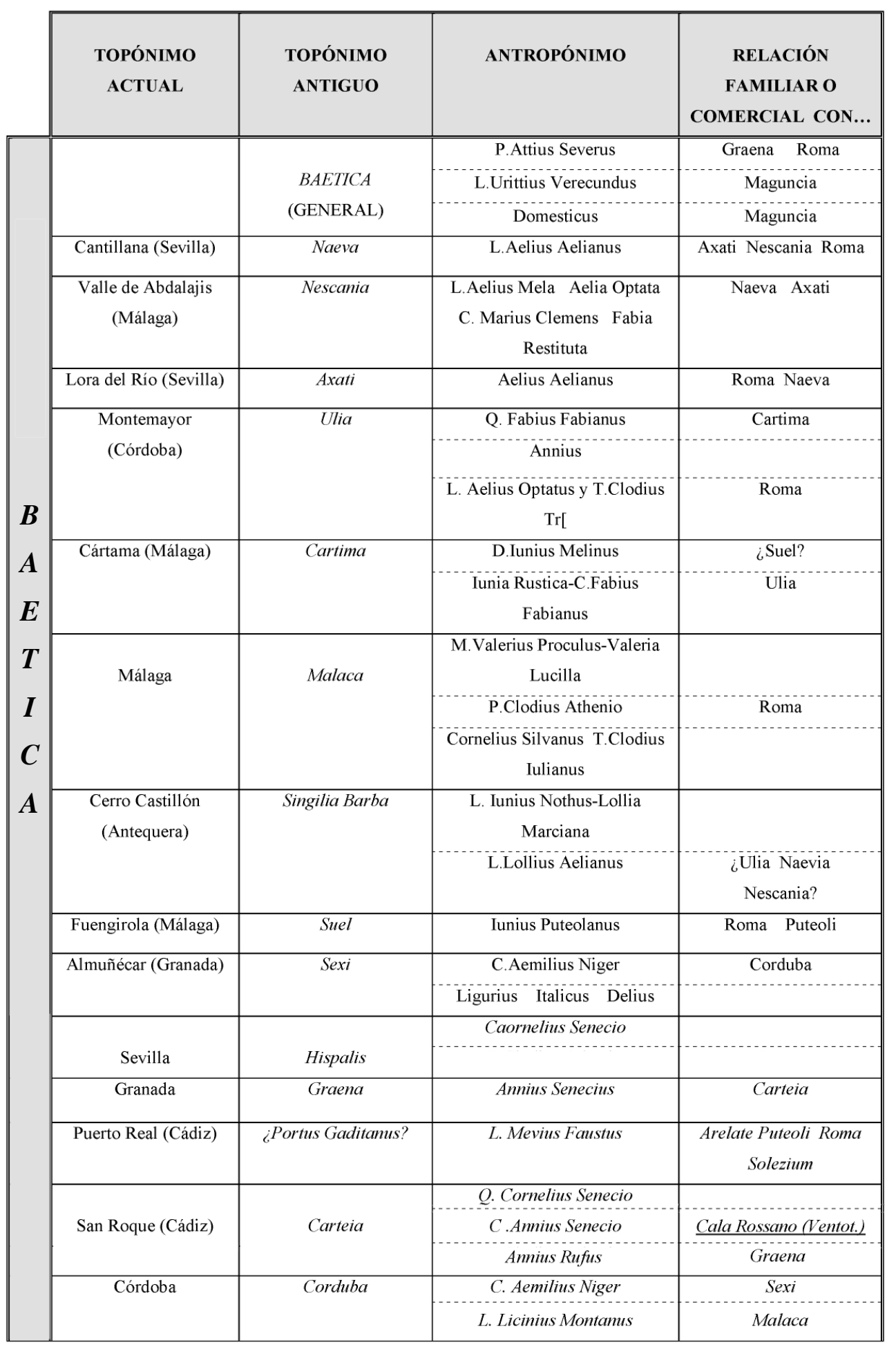

Figura 1 


\section{RELACIÓN DE TOPÓNIMOS Y ANTROPÓNIMOS CITADOS EN EL TEXTO \\ Y SUS POSIBLES RELACIONES [ÁREA EUROPEA]}

(Las localizaciones en pecios aparecen señaladas mediante subrayado)

\begin{tabular}{|c|c|c|c|}
\hline TOPÓNIMO ACTUAL & TOPÓNIMO ANTIGUO & ANTROPÓNIMO & $\begin{array}{c}\text { RELACIÓN FAMILIAR O } \\
\text { COMERCIAL CON... }\end{array}$ \\
\hline Nîmes (Francia) & Nemausus & (Familia de los) Varenii & Plomchard (Douarnenez) \\
\hline $\begin{array}{c}\text { Saint-Romain-en-Gal (Vienne, } \\
\text { Francia) }\end{array}$ & ¿Solezium? & L- Mevius Rufus & Gades \\
\hline Cala Rossano (Ventotene-Ital) & Pandataria (regio) & C. Annius Senecio & Carteia \\
\hline \multirow{3}{*}{ Pompeia (Napoli, Italia) } & \multirow{3}{*}{ Pompeii } & A. Umbricius Scaurus & \\
\hline & & Cecilius Iucundus & \\
\hline & & Aulus Mevius Iulus & Puteoli \\
\hline Plomchard (Douarnenez, Fra.) & ¿? & C. Varenius Varo & Nemausus \\
\hline \multirow{5}{*}{ Roma } & \multirow{5}{*}{ Roma } & P. Mevius Faustus & ¿Gades? \\
\hline & & P. Clodius Athenio & Malaca \\
\hline & & M. Valerius Proculus & Malaca \\
\hline & & P. Attius Severus & Puteoli \\
\hline & & M. Petronius Honoratus & Baetica \\
\hline August (Suiza) & Augusta Raurica & (Familia de los) Uritti & Portus Veneris $\quad$ Maguntia \\
\hline Port Vendres (Francia) & Portus Veneris & Q. Urittius Revocatus & Augusta Raurica \\
\hline \multirow[t]{2}{*}{ Mainz (Alemania) } & \multirow[t]{2}{*}{ Maguntia } & L. Urittius Verecundus & Baetica $\quad$ Augusta Raurica \\
\hline & & (Familia de los) Uritti & Baetica \\
\hline Comacchio (Ferrara, Italia) & ¿? & L.Cae[ Bat[ & ¿Puteoli? \\
\hline
\end{tabular}

Figura 2

claramente inferior a la de Athenio, no es un salsarius en sentido estricto, pero su cursus permite caracterizar a un grupo de comerciantes que encontraron condiciones favorables de promoción social en las relaciones establecidas con las clases rectoras de las ciudades, no con los oficiales del Estado, como en el caso anterior. Iunius Nothus fue un liberto enriquecido que, gracias a su relación matrimonial con Lollia Marciana, enlazó con una familia perteneciente a la clase aristocracia local de Singilia. Una inscripción poco conocida (Serrano et alii 1975) nos informa sobre la dedicatoria otorgada por el municipio a su mujer; el propio Nothus se encargó, junto a los padres de ésta, de aceptar el honor y de pagar la imagen de su bolsillo. De Nothus sabemos además (CIL II, 2023) que el ordo de la ciudad le otorgó una estatua y los máximos honores que podía alcanzar un liberto en un municipio romano y que los cives e incolae (CIL II, 2022) realizaron una colecta para dedicarle una imagen, tras haber promocionado al cargo de sevir perpetuus. Una posterior adlectio inter cives permitiría a Nothus casar con la mencionada ingenua Marciana, en cuya inscripción aparece mencionado como L. Iunius Nothus Corn(elius?) [Q?]uietinus, pues debió alcanzar la ciudadanía local gracias al patronazgo de un miembro de la gens Cornelia (Ordóñez Agulla 1988-89, 339). La inscripción que informa de su nombramiento como sevir resulta singularmente interesante ya que permite establecer la presencia, junto a los ciudadanos de Singilia (cives), de extranjeros (incolae peregrini) seguramente, como el propio Nothus, libertos establecidos en la ciudad por razón de negocios.

Una situación similar a la de Nothus debió tener otro Iunius, en este caso de cognomen Puteolanus (CIL II, 1944), establecido en Suel (Fuengirola, Málaga), probablemente un comerciante itálico de salazones de pescado afincado en Hispania (Haley 1990). La inscripción de Suel está dedicada, como conviene a alguien relacionado con los negocios marinos, a Neptuno Augusto y en ella se indica que tanto la estatua como la comida pública ofrecida (epulum) fueron pagados por Puteolanus, quien había alcanzado la dignidad de sevir Augustalis in municipio Suelitano primus et perpetuus. Así pues, como en el anterior caso del singiliense Nothus, Puteolanus 
alcanzaba los máximos honores que un liberto podía aspirar a obtener en un municipio omnes honores quos libertini gerere potuerunt. La fecha de la inscripción de Puteolanus no puede ser anterior a la de la Lex Flavia Municipalis que concedía el status de municipio latino a las ciudades no privilegiadas de Hispania, pues en la inscripción se menciona a Suel como municipio. Por ello, E. Haley (1990, 76), se muestra prudente a la hora de identificar a Iunius Puteolanus de Fuengirola con el Puteolanus que figura en un ánfora Dressel 8 (CIL XV, 4687), un contenedor de gari scombri flos que formó parte del depósito anfórico de los Castra Praetoria de Roma, cuya fecha de deposición estuvo en torno a la mitad del siglo i d. C. Este desajuste cronológico resulta relativamente intrascendente ya que, en cualquier caso, la vinculación con el mundo de los salsarii por parte del Puteolanus de Suel podría quedar atestiguada por la dedicatoria a Neptuno Augusto, una deidad íntimamente vinculada a este negocio, como muestra la dedicatoria de Plomarch (Douarnenez, Bretaña), a nombre de C. Varenius Varo $(A E 1952,22)$ un personaje relacionado con las salazones, cuyo epígrafe fue hallado en las proximidades de una factoría de salazón ${ }^{4}$. Así pues, Iunius Nothus de Singilia y Iunius $\mathrm{Pu}-$ teolanus de Suel, ambos libertos, junto con Clodius Athenio de Málaga, un libre, parecen buenos ejemplos del ascenso social que a partir de época flavia experimentaron una serie de comerciantes enriquecidos que llegaron a gozar de una situación social relativamente importante en sus ciudades de adopción. En el seno de las mismas, quedaban ligados al típico juego social urbano por complejas relaciones de amistad y/o clientela con las aristocracias municipales y provinciales (López Barja 1991). Lamentablemente, en los dos primeros casos, no podemos certificar una estricta implicación de ambos personajes con la comercialización de salazones, aunque las evidencias apunten a una posibilidad cierta en este sentido. En cualquier caso, la presencia de Nothus y Puteolanus, permite aproximarnos a un posible modelo de promoción social entre comerciantes venidos a más.

${ }^{4}$ C. Varenius Varo fue un ingenuo que ejerció al menos durante cuatro anualidades como curator civium Romanorum en la región, lo que lo hacía responsable de los ciudadanos romanos en una zona escasamente urbanizada. Originario tal vez de Nemausus, donde el nomen Varenius es frecuente y cuyos habitantes pertenecieron, como él, a la tribu Voltinia, Varo debió ejercer alguna función productiva o comercial relacionada con la elaboración de las salsas y las salazones de pescado de la región (Eveillard 2008).

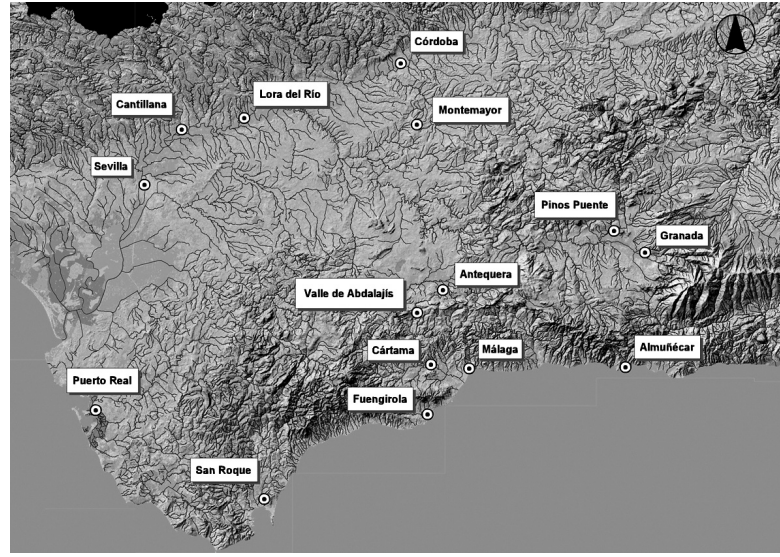

Figura 3. Negotiantes salsarii en Baetica.

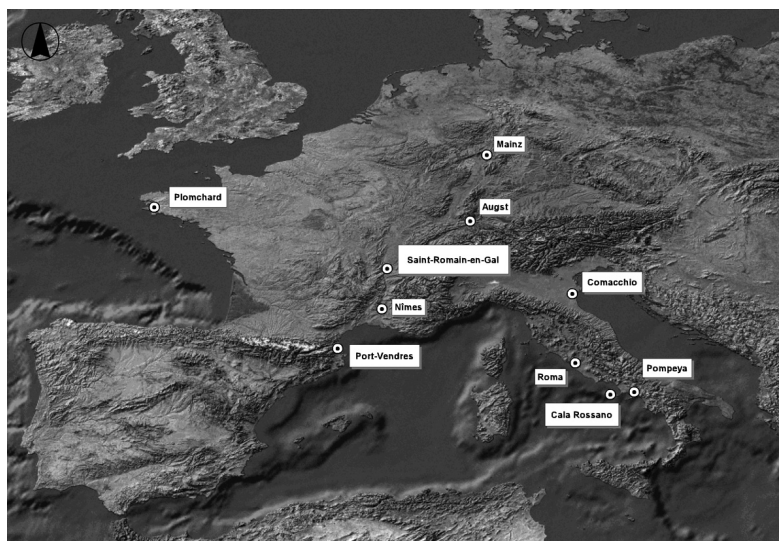

Figura 4. Relaciones de los negotiantes con otros puntos del Imperio.

Un nuevo caso, de cuna más ilustre, es el aportado por C. Aemilius Niger de Sexi (Almuñécar, Granada), cuya filiación completa C. Aemilius Niger Annius, Seneca filius, Arvacus, remite a un poliónimo que parece evidenciar la condición ecuestre de su poseedor. La dedicatoria que recoge su nombre (ILPG, 8) señala que era, o había sido, flamen divorum Augustorum provinciae Baeticae, un puesto que debía ejercerse en la capital provincial. Ésta es la única dignidad que recoge la inscripción aparecida en el entorno de la factoría de salazones de El Majuelo, en Almuñécar, lo que parece relacionar a Niger con la industria salsaria (ILPG 8; Étienne; Mayet 2002, 98 $)^{5}$. Los dedicantes de Sexi, quienes elevaron

${ }^{5} \mathrm{~S}$. Dardaine $(2001,32)$ ha propuesto que el padre natural de este Niger adoptado por un Aemilius debió ser un Annius Seneca. Con tal nombre se conoce a un duovir de Ilurco (Pinos puente) que ejerció su magistratura en época de Marco Aurelio (ILPG 96, 106), y que de ser efectivamente pariente en línea directa del flamen de Sexi constituiría un testimonio claro del ascenso de determinadas familias de notables mu- 
la estatua a Aemilius Niger «eximia pro liberalitate», fueron tres amici de su misma gens cuyos cognomi$n a$ : Ligurius, Italicus y Delius, parecen revelar tanto su condición de antiguos esclavos de la familia como la extensión geográfica de los negocios de su patrón, si es que se acepta el carácter de salsarius de Niger (Étienne y Mayet 2002, 98) ${ }^{6}$. Esta afirmación se vería avalada por el hecho de que fueron precisamente la Narbonense, Italia y Oriente las regiones en las que los comerciantes béticos de salazones han tenido tradicionalmente sus principales intereses económicos. Las dos primeras son, de hecho, las áreas de Occidente con las que se mantuvo un tráfico más intenso a lo largo de los siglos I y il d. C., como demuestra la distribución geográfica de las ánforas sudhispanas del Mediterráneo y los altos porcentajes de ánforas galas en puertos de la Bética, como en el caso de Hispalis (García Vargas 2007). El tráfico con Oriente, siendo más escaso, no fue por ello inexistente, ya que el vino rodio presente en el puerto de Sevilla entre épocas flavia y antonina supone casi el $8 \%$ del total de los caldos importados durante el período, frente a un 36\% aprox. de vinos galos (García Vargas 2007). Además, en el siglo II d. C. se fechan dos inscripciones sepulcrales griegas procedentes de la necrópolis romana de la Trinidad (Ordóñez Agulla 2005), lo que testimonia la presencia de orientales en la ciudad en momentos altoimperiales.

Asimismo, el caso de Málaga, permite testimoniar la presencia de comerciantes orientales y su integración y promoción en sus ciudades de destino, como se deduce de una inscripción en griego (IG XIV, 2540) en la que se menciona a una corporación de mercaderes sirios y asia[nos?]. Éstos, a través de su curator Cornelius Silvanus, realizan una dedicatoria a T. Clodius Iulianus, quien aparece calificado como patrono y presidente de la asociación profesional. El personaje honrado en la inscripción lleva el mismo nomen que el anteriormente referido Clodius Athenio y dado su cargo de presidente (prostatés) de la corporación, debió ser él mismo un comerciante. La presencia de dos individuos de nomen Clodius en relación con dos asociaciones diferentes de comerciantes que actúan en la misma ciudad puede indicar la existencia de estrechas relaciones entre los

nicipales cuyos anhelos de promoción socio-política parecen haberse ligado también a la movilidad geográfica, en este caso hacia la capital provincial (Melchor 2006).

${ }^{6}$ De ser así estaríamos ante un ejemplo más de la extensión del concepto de amicitia para referirse también a relaciones personales que fueron en realidad de dependencia o de patronazgo (Pérez Zurita 2006, 347-349). Por otra parte, las referencias geográficas podrían ser una evidencia más de la importancia de la origo para aprehender conexiones comerciales (Pavis d'Escurac 1988). diversos corpora de negotiantes presentes en Málaga. La corporación de negotiantes Malacitani y la de los comerciantes Sírioi kaí Asía[oi?] podrían hallarse enlazadas entre sí gracias al patronazgo de personajes de la primera sobre la segunda. De hecho, aunque una corporación profesional podía esperar de su patrón asistencia legal y consejo comercial, la principal tarea era la intermediación en las relaciones con las instituciones, con otras asociaciones y, en general, con cualquiera con el que el colegio implicado deseara relacionarse (Verboben 2007).

Así pues, todos estos ejemplos sobre agentes de comercio y sus múltiples orígenes, así como la magnitud geográfica de los negocios del Niger de Sexi y la posible relación de Athenio con el resto de los corpora de comerciantes activos en Malaca, nos advierte de las multiformes conexiones entre grupos y de la extraordinaria complejidad que se deduce de las diferentes situaciones socio-políticas de los personajes involucrados en el comercio.

Aunque el esquema que estamos ensayando no deja de ser un primer esbozo inicial en el que todas estas situaciones sociales no están definidas de forma unívoca, resulta evidente que tales situaciones, así como las actuaciones personales de determinados individuos, podían permitir a ambiciosos particulares medrar en el sistema para acceder a una más eminente situación social. En el caso de Niger, la dignidad de flamen le permitió mejorar aún más una situación personal ya de por sí bastante favorable. En el de Athenio, su especial vinculación con la prefectura de la Annona a través de personajes como Marcus Valerius Proculus, malagueño quizás él mismo, lo debió convertir en referente social y económico para el resto de los comerciantes activos en la ciudad, al tiempo que le ofrecía posibilidades de promoción social al otro lado del mar Mediterráneo. De hecho, la inscripción funeraria de Athenio en Roma, ya referida, testimonia que fue en la capital dónde ejerció fundamentalmente su actividad; aquí era además donde la exhibición pública de su carácter de quinquennalis del corpus negotiantium Malacitanorum tenía sentido, pues fuera de su patria chica la corporación se convertía en marco social de referencia del individuo y lo ubicaba en un lugar determinado del orden social subaristocrático de la ciudad (Verboben 2007).

En cualquier caso, los datos aportados en los párrafos anteriores nos permiten reflexionar sobre la movilidad geográfica de los negotiatores de la Bética, fueran éstos libres o libertos. Este hecho habitual implicaba a veces el desarraigo respecto a sus comunidades de origen así como la integración en la comunidad de acogida. Tal fue el caso del Puteolanus de 
Suel, honrado con la primacía del colegio de seviri de la ciudad, y de Iunius Nothus de Singilia Barba, quien además obtuvo la adlectio inter cives y llegó a emparentar con una familia de la aristocracia local. Así pues, los colegios de seviri se comportaron de hecho, gracias a su poder económico, como un segundo ordo de rango menor capaz de incluir en el juego social a individuos de extracción social poco brillante (Stylow; Gimeno Pascual 2001, 106).

Otros libertos de mayor capacidad o con patrones más poderosos, así como la mayoría de los libres, emigraron igualmente de sus comunidades de origen, pero lo hicieron hacia lugares donde las posibilidades de promoción social se vinculaban a las necesidades del ejército o a los oficiales de la administración imperial, algo que venía suscitándose de forma genérica desde la época julio-claudia ${ }^{7}$. Este camino lo emprendieron los ya citados Aemilius Niger, de Sexi, quien desempeñó el flaminado provincial en Córdoba, y de forma más evidente Clodius Athenio de Málaga, cuyo domicilio en Roma y cuya presidencia de la asociación de negotiatores Malacitani le permitió relacionarse directamente con el prefecto de la Annona.

Este interés por favorecer y honrar a los magistrados de la Annona, queda singularmente explicitada en el caso de los comerciantes de aceite, ya que el sucesor de Valerius Proculus entre 144 y 146 como prefecto de la Annona, M. Petronius Honoratus, también fue a su vez honrado en la capital por un colegio de negotiatores olearii ex Baetica (Chic García 1993, 15) ${ }^{8}$. Así, numerosos armadores y comerciantes béticos se beneficiaron, gracias a su colaboración con la administración annonaria (Chic García 1983, $171 ; 1988,57$ y ss.), de ventajas fiscales e incluso de la exención del desempeño de las magistraturas urbanas en sus comunidades de origen. Ésta es seguramente la razón por la cual difícilmente aparece en el cursus de estos individuos el desempeño de empleos civiles, con excepción de los sacerdocios provinciales que los vinculaban directamente a la figura del emperador a través del Concilium Provinciae ${ }^{9}$. En

\footnotetext{
${ }^{7}$ No se debe minimizar la importancia que revistió el abastecimiento del ejército y las múltiples complejidades económicas que ello implicaba. A este respecto, para un caso concreto en Hispania véase Carreras-Monfort 2006 o, de forma extensa, la obra en que se incluye este trabajo.

${ }^{8}$ Los curatores eran entonces D. Caecilius Hospitalis y Cassius Faustus (CIL VI, 1625b). Además, D. Caecilius Hospitalis aparece en solitario como diffusor olearius en ánforas Dressel 20 de los años 145 y 147 (CIL XV, 3762-3764; Rodríguez Almeida 1974-1975). También aparece asociado a D. Caecilius Maternus en 154 (CIL XV, 3769-3781) y a D. Caecilius Onesimus en 149 (Rodríguez Almeida 1972).

${ }^{9}$ Este debió ser el caso de L. Licinius Montanus, un malagueño destacado cuya ciudad le erigió una estatua en la ca-
}

ambos casos, las posibilidades de promoción de los negotiatores se derivaron de su posición preeminente en las respectivas asociaciones profesionales, las cuales funcionaron como afinados instrumentos de impulso social. De hecho, la pertenencia a tales asociaciones profesionales significó para estos individuos un lazo solidario de grupo más permanente que el constituido por las societates unius negotiationis que refleja la epigrafía anfórica y en las que solían unirse de forma eventual para realizar sus viajes de negocios. Pero, sobre todo, constituyó el vínculo jurídico fundamental que los unió a intereses públicos de los que se derivaron, además de beneficios sociales, inmunidades fiscales importantes.

Por tanto, a partir del siglo II d. C. la consolidación de la administración imperial dedicada a los abastecimientos estatales estaba poniendo en las provincias occidentales las bases para la promoción social de individuos y grupos sociales entre los que se encontraron los negotiatores ex Baetica. En el caso de estos últimos, la articulación de su labor a través de los colegios profesionales que los agrupaban parece haber sido una condición necesaria para su elevación social que fue paralela a la dignificación progresiva de unas corporaciones de comerciantes que comenzaban a sustituir en el transporte de los géneros estatales a las compañías que arrendaban el servicio en época julio-claudia (Chic García et alii 2001, 370). No sorprende entonces que el jurista Gayo (Digesto III. 4.1) recoja entre los colegios a los que se les concede la consideración de corpus el de los navicularii qui in provincia sunt.

Desde luego, queda claro que no todas las corporaciones gozaron del mismo favor y la misma consideración por parte de las instancias oficiales. Las dedicadas al comercio del aceite parecen situarse en un status singularmente privilegiado, ya que los olearii ex Baetica parece haber desempeñado un papel fundamental en la política annonaria de los emperadores del siglo II d. C. Un pedestal recientemente descubierto en la cimentación del campanario de la Catedral de Sevilla, la popular Giralda, y editado por uno de nosotros en colaboración con otros autores (G. Chic y otros 2001; Remesal Rodríguez 2008), califica a este corpus de splendidissimum, a la vez que indica el carácter de algunos de sus miembros como diffusores olei ad Annonam Urbis. La posición especial de los diffusores olei con respecto a la administración imperial y su misma especialización funcional se derivó del interés específico del Estado por una

pital provincial, donde a fines del siglo II d. C. fue flamen provincial y gozó de la consideración de cives adlecto Cordubensi (Melchor Gil 2006, 258). 
materia, el aceite, que junto al trigo fue objeto prioritario de la política estatal de abastecimientos. Pero en el caso concreto de las salazones, nuestro Clodius Athenio de Malaca se califica a sí mismo con el término comercial más genérico de negotians (salsarius $)^{10}$, por tanto, Athenio, como seguramente Cornelius Niger o Iunius Puteolanus fueron salsamentarii con cierta cualificación social y profesional. La diferencia entre la labor del negotians y la del mercator residiría no tanto en la capacidad financiera, menor en el segundo, sino en la situación específica del primero con respecto sus negocios, ya que les confería una posición especial en relación a la producción de bienes con vistas al mercado (Verboben 2006); es decir, les permitía establecer una tupida red de negocios que afectaba tanto a la esfera productiva como a la comercial, sin romper por ello la unidad de su negocio ${ }^{11}$.

Esta posición de los negotiatores con respecto al suministro alimenticio de sus comunidades los haría cada vez más necesarios para éstas y justificaría en cierto modo su capacidad manifiesta de ascenso en la jerarquía ciudadana. Ello resulta especialmente evidente en el caso del Puteolanus de Suel o en el del conocido Umbricius Scaurus de Pompeya, a quien la epigrafía de la ciudad, así como los tituli sobre urcei y otro tipo de contenedores (Curtis 1979; 1984), nos muestran empeñado tanto en la producción como en la distribución regional de las salsas de pescado, lo que

\footnotetext{
${ }^{10}$ En esta época imperial avanzada, el término negotians había transitado ya un largo camino que, sin hacerle perder su contenido semántico inicial, vinculado genéricamente al desempeño de una actividad empresarial cualquiera relacionada con el mercado, lo había desvinculado progresivamente del simple comerciante. Como señala G. Chic García (2009): «aunque los negotiatores - caballeros o no- pudiesen comerciar en altos niveles financieros, no se puede decir de ellos que fuesen comerciantes de lo concreto (mercatores). Ellos, como los nobiles, invertían sus ganancias en el único bien que se consideraba realmente sólido y honorable, la tierra. Y, como antaño, las relaciones familiares, las amistades y las clientelas, formaban una tupida red que sostenía el mundo de los negocios, sin necesidad de recurrir al establecimiento de instituciones financieras especializadas, como podrían ser los bancos». Por tanto, a tenor de estas palabras vemos cómo los grandes señores de Roma prestaban dinero a negotiatores, dinero que circulaba a través de toda la red de clientela y de esclavos dentro de estructuras piramidales de enorme complejidad (Chic García 2009).

${ }^{11}$ A pesar de lo cual, dicho término, especialmente en los primeros tiempos, arrastraba el estigma social del desprecio con el que se consideraba el trabajo manual y la actitud crematística y que no se solía emplear nunca para mencionar a un miembro del ordo equester involucrado en el comercio, prefiriéndose utilizar perífrasis que alejen a personajes de elevada cuna de un ejercicio profesional del comercio (Valencia 1989-90, 209). Algunas cuestiones generales sobre el comerciante romano, en este sentido, pueden verse en Chic García (2009); asimismo, sobre el comercio a través de personas interpuestas (institores) ver Aubert (1994).
}

permite incluirlo en la categoría de negotians, aunque no aparezca nunca calificado explícitamente como tal.

Así pues, puede entenderse la importancia de mercatores, negotiatores y navicularii para la administración annonaria del Estado ya que, como se ha señalado, ésta fue reduciendo desde fines del siglo I d. C. su dependencia de las compañías arrendatarias de suministros al tiempo que promocionaba a los collegia profesionales como instancias encargadas de la gestión y el transporte de los géneros fiscales. También se ha indicado que este proceso benefició especialmente a los colegios profesionales de olearii, pero parece lógico aceptar que los comerciantes al servicio de la Annona no se limitaron a la gestión de las mercancías annonarias por excelencia, el aceite y el trigo, sino que su actividad alcanzó igualmente a la adquisición y el transporte de cualquier otra materia, alimenticia o no, de la que el Estado tuviese necesidad (Herz, 1988, 72-73). De hecho, el Estado debía encontrar ventajoso tratar con las corporaciones mejor que con los individuos aislados, aunque fuera de una manera menos formalizada y burocratizada que en el caso de los productos subvencionados. Es en este contexto en el que también los colegios de salsarii o los de transportistas de ciudades concretas (como los malacitanos) pudieron beneficiarse de las ventajas económicas que les reportaba su relación con la administración imperial.

En cualquier caso, para poder reconstruir la génesis del complejo proceso que aquí vemos consolidado, conviene retroceder a la época altoimperial inicial, un siglo antes.

\section{ORIGEN DE LOS SALSARII EX BAETICA EN EL SIGLO I D. C.}

Tanto la documentación epigráfica como la «literaria» referida a los comerciantes de salsas béticas, con anterioridad a la época de los Antoninos, parece sugerir que en el siglo I d. C. no existió una comunicación tan estrecha entre altos oficiales del abastecimiento estatal y los productores-comerciantes de salazón, sino que estos últimos basaron su prosperidad en la libre concurrencia, aunque sin excluir taxativamente los intereses del Estado en este mercado, lo que fue posibilitando su incipiente promoción. Tal vez podamos tener una visión global sobre esta cuestión gracias a distintos personajes como L. Mevius Faustus, P. Attius Severus $o$ L. Vrittius Verecundus; todos ellos igualmente prósperos, aunque se situaban de forma ligeramente distinta respecto al mercado de las salazones béticas, lo que resulta ilustrativo para 
conocer los diferentes puntos de partida de los grupos de comerciantes.

Como salsarius ejerciendo su oficio sobre bases completamente privadas podemos considerar a L. Mevius Faustus, a cuyo nombre aparece sellada una partida de ánforas de salazón hallada en un almacén derruido del alfar de Villanueva (Puerto Real, Cádiz), en época flavia (García Vargas 1998, 234). Mevius Faustus perteneció a una vieja familia de comerciantes con inmuebles en Cádiz y negocios en Arlés, Puteoli y Roma (Parodi Álvarez 2004); fue con bastante probabilidad descendiente del mercator L. Mevius Rufus quien está consignado en una Dressel 12 bética hallada en Saint-Romain-en-Gal (Vienne) y fechada en época augustea (Desbat et alii, 1987: SRG, no 6). Asimismo, debió ser familiar, en línea más próxima, de P. Mevius Faustus (CIL XV, 3663), a cuyo nombre está signada una Dressel 20 olearia hallada por Dressel en los Castra Praetoria de Roma (hacia 50 d. C.). Precisamente, coetáneos a Mevius Rufus encontramos (Digesto 32.1.41.6; Javoleno) a unos Mevii como receptores por fideicomiso de un legado que incluía posesiones en la ciudad de Cádiz (Chic García 2004 94).

Hacia el 37 d. C. se conoce a otro Mevius, en este caso Aulus Mevius Iulus, como testigo de una interesante operación comercial. Se trata de un préstamo de 13.000 sestercios que un tal Hesychus, esclavo del liberto imperial Evenus Priamus, hizo a C. Novius Eunus (Tabula Pompeiana Sulpiciorum, 51), recibiendo de éste como garantía 7.000 modios de trigo alejandrino junto a otros 4.000 modios de cereal y legumbres secas. El préstamo tuvo como objeto una operación especulativa a corto plazo que debía permitir a Hesychus aumentar el monto recibido en préstamo, devolverlo con sus intereses correspondientes y recuperar con ello los 11.000 modios de trigo y legumbres dejados en garantía, que a su vez reportarían, antes del final de la temporada de navegación, nuevas ganancias comerciales camino de Roma (Virlouet 2000, 144). Esta operación muestra cómo los agentes de comerciantes y transportistas de géneros al por mayor podían aprovechar la estancia de las mercancías en los almacenes de los puertos de ruptura de carga para hacer negocios aprovechando la coyuntura. Asimismo, ilumina la forma en que el comercio local — sujeto a operaciones financieras a corto plazo- y el internacional — para el que eran precisos plazos de amortización más prolongados-, podían relacionarse y retroalimentarse para la consecución de nuevos beneficios ${ }^{12}$.

\footnotetext{
12 Sobre el carácter de estos préstamos a más largo plazo entre comerciantes puede servir de referencia el citado paso
}

Operando a una escala menor, pero en la misma esfera de negocios privados internacionales, encontramos al segundo protagonista, P. Attius Severus a quien conocemos como comerciante de salazones béticas por los tituli picti de los Castra Praetoria (CIL XV, 474849), así como por una de las tablillas del archivo de los Sulpicii de Puteoli (TPSulp, 13) en la que se menciona cómo a través de uno de sus esclavos, de nombre Primus, contrata en 38 d. C. un servicio de transporte marítimo a un naúkleros cario llamado Menelaos. Los documentos son meros recibos redactados de conformidad a las cláusulas de un contrato perdido y retienen de éste tan sólo la indicación de que el precio pactado del transporte fue de 1.000 denarios y que, en caso de siniestro, el transportista se comprometía a devolver el monto del alquiler de la nave al comitente, actuando como garante de la operación un tal M. Barbatus Celer (Camodeca 1999) ${ }^{13}$.

Los casos de Mevius Faustus y de Attius Severus nos muestran por tanto a los salsarii béticos implicados en el comercio, el mundo de las finanzas y los créditos, además del mercado inmobiliario y la producción de ánforas (en el primer caso). De este modo, es posible entender mejor el origen de la fortuna de negotiatores salsarii, sean éstos libres o libertos, quienes posteriormente tendrán la oportunidad de integrarse en el orden social del sus comunidades de adopción o en el nuevo orden supraciudadano que progresivamente imponía la acción del Estado.

Por su parte, el tercer personaje citado, L. Vrittius Verecundus, es un activo negociante en salsas béticas perteneciente a una conocida gens de comerciantes galos implicados en el transporte de diferentes alimentos, tales como vino, aceite o las mismas salazones (Blänsdorf 1985, 91 y ss.). Ánforas con el nombre de nuestro protagonista han sido halladas recientemente en el Hopfengarten de Maguncia (Martin-Kilcher 2002; Ehmig 2003). De las diez ánforas salsarias del tipo Beltrán IIA que forman el depósito de Maguncia, cinco llevan el nombre de

de Digesto (32.1.41.6, Javoleno). En él, se pregunta al jurista si la expresión empleada por el testador con respecto al legado que hace a los Mevii, incluyendo en él «quidquid in patria Gadibus possideo» debe entenderse como inclusiva de una posesión suburbana, un libro de cuentas (kalendarium) que el testador dejó al morir y el dinero que había ingresado de unos créditos y que se encontró en la casa de Cádiz. El jurista considera explícitamente al kalendarium y el dinero como excluido del legado. Tal kalendarium debe haber sido un libro de cuentas ajeno a la administración de la casa legada, por cuanto no se incluye en la herencia, pero que recogería contraídas deudas por terceros, lo que lo convertía en motivo de disputa entre los herederos.

${ }^{13}$ A este respecto, Gofas (1993) interpreta la cantidad desembolsada como una especie de seguro marítimo por el valor de la mercancía en el caso de pérdida de ésta. 
Verecundus en posición diversa en los tituli, lo que significa que éste aparece cumpliendo funciones distintas en la misma cadena comercial pues, además de abastecerse directamente en la Bética ${ }^{14}$, compraba en un puerto de ruptura de carga, que pudo ser Lugdunum, a intermediarios como Proculus y Urbicus, una de cuyas ánforas parece formar parte de un lote de treinta y cinco contenedores; mientras, otra se adquirió junto a setenta y cuatro más, puesto que el número que aparece registrado en posición $《 F$ » es —LXXV— (Martin-Kilcher 2002; ánforas 4 y 5 especialmente $)^{15}$. Es interesante constatar cómo ambas ánforas, pertenecientes a partidas diferentes, fueron adquiridas a su vez por estos mercatores a un mismo productor, que aparece en posición «E», y cuyo nombre fue Domesticus. Aunque siempre debemos considerar los cálculos cuantitativos con la conveniente prudencia, no deja de ser interesante recalcar que si admitimos una capacidad media de 391 para las ánforas de Maguncia, las dos partidas adquiridas por Proculus y Urbicus a Domesticus suponen una cantidad total de $32901(1365+2925)$, o lo que es lo mismo, 3, $29 \mathrm{~m}^{3}$ de salazón de pescado. Esta cantidad viene a ser la décima parte de la capacidad total de cada uno de los saladeros excavados en Baelo Claudia (Étienne y Mayet 1993-1994, 210), lo que significa que un solo intermediario podía acaparar (¿o gestionar?) con cierta facilidad la producción de una sola officina con idea de revenderla en plaza o en un punto intermedio a otros comerciantes de mayor capacidad económica.

Lo expuesto hasta este momento, dibuja un panorama más complejo, y en cierto modo, inverso al planteado hace ya años por Robert Étienne (1970), quien, a partir de la conocida expresión garum sociorum y las inscripciones $-S$. $C E T-$ y $-S C G-$ del alfar de El Rincocillo (¡en Algeciras!) proponía la dedicación a la actividad salazonera de una única societas arrendataria de los derechos sobre la sal gaditana ${ }^{16}$. Sin poder desechar radicalmente esta in-

\footnotetext{
${ }^{14}$ Especialmente el ánfora $\mathrm{n}^{\mathrm{o}} 6$ de las publicadas por $\mathrm{S}$. Martin-Kilcher, pág. 347, fig. 5, perteneciente, según su registro «F», a una partida de 16 ánforas.

${ }^{15}$ Estos controles numerales son fruto de una discusión aún inconclusa. A veces, aparecen en forma de grafito y no pintados mediante atramentum u otra tinta, como fue el caso de un hallazgo que uno de nosotros tuvo ocasión de publicar en su día y en el que se recoge la discusión sobre estas interpretaciones (Laubenheimer, Martínez Maganto e Hillaret 1993).

${ }^{16} \mathrm{La}$ sal es otra de las industrias extractivas sujeta a los intereses de productores y comerciantes de salazones, quienes bien pudieran haber participado de diferentes formas en los negocios de explotación de la misma, como actividad complementaria de la industria salazonera. Sobre estas cuestiones sal-salazones ya hemos tenido ocasión de profundizar
}

terpretación, parece más razonable interpretar el apelativo garum sociorum como simple sinónimo de garum Hispanum (Millán León 2001). Así pues, este fragmentado mundo comercial caracterizado por una relativa independencia de las actividades productivas, precisaría una serie de mecanismos de racionalización y coordinación de actividades para su posterior comercialización exterior, algo que, debemos insistir, no puede haber sido realizado más que por los comerciantes que operan a grandes distancias.

El caso de Verecundus nos recuerda que si bien este tipo de comercio de larga distancia parece haber estado mayoritariamente en manos de privados, los arrendatarios de suministros para el Estado no debieron ser ajenos al mismo. De hecho, la actividad de este comerciante se ajusta bastante a la que cabe esperar de un intermediario presente en los lugares de origen y de recepción final de las mercancías demandadas por el Estado, pero también en los puntos de ruptura de carga, como Lyon, donde la libre actividad comercial generaría un mercado activo de estas mismas mercancías. La particularidad de las ánforas salsarias del eje Ródano-Rin, reside en la anteriormente referida presencia de un conjunto de cifras que cuantifican las partidas de ánforas (Martin-Kilcher 2002, 347), lo que no es incompatible, con un control de la actividad comercial por parte de gestores de la misma, situados en un nivel superior al de los pequeños comerciantes de los que se abastecían. Este tipo de funcionamiento no es imposible en un ámbito estrictamente privado de actuación, pero su constatación en un área mercantil de interés prioritario para el Estado, unido a la frecuencia creciente con la que se documentan en los tituli sobre ánforas y a las indicaciones de oficiales del ejército o de la Administración como destinatarios de los recipientes (Ehmig 1995, 1996; Ehmig y otros 2004), así como la preeminencia misma de grandes transportistas como los Vritii en el trasiego comercial de la zona, apuntan probablemente a una organización comercial orientada hacia el principal consumidor de la región: la administración, civil y militar del Estado romano, tal y como ocurre en otros zonas de fuerte presencia militar (Carreras 1997; para la situación en los siglos II y III d. C. véase Menéndez Argüín 2004).

Como ya se ha comentado, no deja de ser llamativo que estos mismos Vritii aparezcan como mercatores de otros productos béticos en contextos temporalmente próximos al de Maguncia, como el pecio Port-Vendres II (Colls et alii 1977) en cuya carga

en diferentes publicaciones (Martínez Maganto 2005; García Vargas; Martínez Maganto 2006; Martínez Maganto y García Vargas e.p.;). 
hallaron acomodo ánforas olearias y vinarias de los tipos Dressel 20 y Haltern 70 con tituli de Q. Vrittius Revocatus. El nomen Vrittius aparece igualmente en signacula sobre Dressel 20 fechados en Augst o Avenches; uno de estos sellos de Augst, datado entre 50 y 90 d. C., con la lectura -QV.R - ha sido desarrollado (Martin-Kilcher 1987, 140) como —Q(inti) V(ritii) R(evocati)— (véase Berni 2008, 599 2137). Esto indica una diversificación de intereses de los negotiatores, que llegan a intervenir de algún modo también en el campo de la producción de envases. Igualmente, se conoce este gentilicio sobre otros contenedores de productos alimenticios, como los toneles de madera ${ }^{17}$.

Una nueva pista sobre la compleja y multiforme actividad comercial la tenemos en la presencia de lingotes metálicos en los mismos barcos que transportaron estas ánforas, como es el caso de los lingotes de plomo del pecio de Comacchio, fechado en los últimos decenios del siglo I a. C. (Berti, 1990). Su disposición, así como las superposiciones de los sellos, han permitido reconstruir un hipotético escenario comercial en el que un par de asociados, representados por las marcas — AGRIP( ) - y - L. CAE( ) BAT( ) - , parecen haber actuado como intermediarios comerciales adquiriendo en el entorno de Cartagena el plomo de otros comerciantes que a menudo llevan nomina coincidentes con los de las grandes familias productoras de plomo en la región durante el siglo II a. C. Finalmente, lo revendían a un distribuidor final, cuyo barco se hundió con la carga junto a la costa adriática del entorno de Ferrara $^{18}$.

Si la marca - AGRIP( ) - representase a Marco Vipsanio Agripa, el yerno de Augusto, los ligontes del pecio de Commacchio, al igual que una pieza

\footnotetext{
${ }^{17}$ S. Martin-Kilcher (1990) señala la existencia de un tapón de tonel con la marca - VRITTI P H-, descubierto en Lyon, reutilizado en el interior de un ánfora del siglo I d. C. (ver asimismo A. Desbat 1991 y, más recientemente, E. Marlière 2002). Ésta última autora recoge varias referencias más, como - VR[ - en un tonel de Vindolanda o - VRITTIFES- en Fos-Sur-Mer (Marlière 2002, 115-116). Probablemente el nombre Vrittius es un gentilicio celta atestiguado en Roma y otras muchas localidades como La Narbonense, Burdeos o Sens, que suele aparecer bajo diferentes variantes nominales (CIL VI, 16098; CIL XII, 1684; CIL XIII, 784...; ver referencias completas en Marlière 2002, 116 ns.185 y ss.). Quizás se trate, efectivamente, de una familia amplia afincada en la Galia y la Bética y dedicada a la producción de envases y al transporte (Colls et alii 1977, 74).

18 Existe una serie de interesantes planteamientos sobre estos plomos referidos a la producción e interpretación comercial de los mismos, aunque se aleja momentáneamente del objetivo de este trabajo merece ser tratado en otro momento. Al respecto consultar el trabajo de $\mathrm{M}^{\mathrm{a}} \mathrm{P}$. García Bellido (1998) con referencias anteriores, así como el de C. Domergue (2007).
}

aislada con la misma inscripción procedente de Ibiza (Rodá 2004), nos pondrían ante una situación en la que el poderoso Agrippa aparecería, asociado a otro individuo, como negotiator plumbarius. El propio Domergue sugiere que los lingotes de Commacchio (noventa y seis en total) son una pequeña parte de una producción mayor de plomo controlada por negotiatores como Agrippa y dirigida hacia Puteoli para subvenir necesidades oficiales, entre ellas, por ejemplo, la construcción de aquae publicae, labor en la que sabemos que el mismo Agrippa estuvo empeñado. Si se acepta esta idea, un personaje de primer orden, de quien hay que recordar que fue duumvir honorario en Carthago Nova y patrono de la ciudad (AE 1997, 366), estaría actuando como proveedor de una mercancía de interés para el Estado, lo que no le impidió lucrarse aprovechando los fletes oficiales para hacer negocios privados.

En este punto, merece la pena recordar una noticia de Estrabón (3.2.10) según la cual las minas hispanas habrían pasado a manos privadas desde época de $\mathrm{Au}$ gusto. Se refiere el de Amasía, seguramente, a la progresiva sustitución de las societates mineras republicanas ${ }^{19}$ por arrendatarios o beneficiarios particulares que compraban a perpetuidad al Estado los derechos de explotación de las minas o los recibían por donación imperial. Esto sugiere una posible vía para entender el origen del súbito enriquecimiento de familias hispanas (Chic García 2005), como la Annaea, que fue la del cordobés Séneca, y la Annia, con raíces en la zona de Sierra Morena. Por tanto, no es improbable que esta nueva pujanza económica haya que buscarla no tanto en la propiedad de tierras, como en la de las minas de cobre y de oro cuyos dueños y/o arrendatarios, tal como mucho después indica el jurista Gayo, «publicanorum loco sunt» (Digesto 39.4.13 pr.) ${ }^{20}$.

Así pues, encontramos de nuevo en fechas tempranas y afectando a personajes de distinta situación social una relación comercial entre personas concretas y negotia diversos, aspecto que hemos señalado como característica definitoria de la función del negotiator

\footnotetext{
${ }^{19}$ Sobre cuyo testimonio existen referencias en las series numismáticas mineras, como en Castulo (Linares) en Jaén (García-Bellido 1986). Estas societates debieron ser, como indica A. Mateo (2001), más bien sociedades arrendatarias de la recaudación de los impuestos en los saltus mineros, aunque G. Chic (2008) estima que también estarían encargadas de las grandes obras de infraestructura minera necesarias para la puesta en explotación de los cotos. En cualquier caso, no parecen tener mucha relación con las más modestas sociedades de comerciantes constituidas a menudo para cada operación comercial entre personajes emparentados.

${ }^{20} \mathrm{Se}$ incluyen en esta categoría de «minas» tanto las canteras como las salinas. Debemos entender que depende de ellos la percepción del vectigal debido al Estado por los eventuales subarrendatarios de los pozos mineros.
} 
durante el Alto Imperio romano. La epigrafía sobre ánforas salsarias béticas del siglo I d. C., que constituye el grueso de la evidencia epigráfica sobre la industria de las salazones para esta época (Lagóstena 2002-3), nos muestra a una fracción de quienes comerciaban y traficaban desde la esfera privada con salazones de pescado que, al igual que en el caso del metal, el vino o el aceite, constituyen un conjunto de mercancías que reclamaban la atención del Estado, al tratarse de productos necesarios para su abastecimiento.

Todo este conjunto de evidencias invita a reflexionar sobre una cuestión, hasta ahora eludida, pero sobre la que ahora merece la pena centrar la atención... ¿Hasta qué punto los salsarii ex Baetica del siglo II d. C. y los aparentemente más modestos mercatores-negotiatores del I d. C, entre los que predominan los libertos (Étienne; Mayet 1998), constituyen sólo la parte visible de una elite comercial en la que debemos considerar también integradas las familias de los órdenes superiores de la sociedad romana?... Es el momento de afrontar este interrogante tras considerar los elementos de juicio que se han ido desgranando en las páginas anteriores.

\section{NEGOTIATORES SALSARII Y ELITE SOCIAL}

La respuesta a esta cuestión no se explica mediante la simple afirmación de que la elite social bética se hallaba involucrada de algún modo en la actividad productiva y comercial, algo que ya resulta obvio, si bien la presencia de las aristocracias en el comercio siempre ha sido materia objeto de debate (Pavis d'Escurac 1977; D'Arms 1981; Whittaker 1985). De lo que se trata, es de saber en qué medida y con arreglo a qué mecanismos se verificaba esta relación. Por una parte, cabe considerar el caso de aquellos comerciantes cuyo enriquecimiento abrió la puerta de entrada a los órdenes superiores de la jerarquía romana a sus descendientes; por otra, los que ya eran miembro de la elite, los senadores y caballeros, que participaron en estos negocios como un campo más de actuación económica.

El primero de estos casos puede venir definido por el dossier epigráfico de los Anni. El primer dato lo aporta C. Annius Senecio quien figura entre los salsarii consignados en las ánforas del pecio de Cala Rossano (Arata 1994, 484), en la primera mitad del siglo I d. C. Tal vez se trate del mismo personaje nombrado en una inscripción funeraria de Carteia, fechada a mediados del siglo i d. C., como perteneciente a la tribu Galeria, la propia de la ciudad $(A E$
1981, 518). Ésta es también la tribu de un supuesto descendiente suyo llamado Q. Cornelius Senecio Annianus (CIL II 1929), que fue cónsul sufecto con Antonino Pío (Caballos 1990, vol. 1, 112-113), y que había comenzado su carrera como sacerdote del Hércules de Carteia (Castillo 1982, 470-71). Como indica su nombre, Senecio Annianus había conseguido emparentar con una ilustre familia sudhispana, la de los Cornelios, descendientes a su vez del caballero Cornelius Senecio, amigo y cliente de Lucio Anneo Séneca. De él nos dice Séneca (Ep 101.3.1) que era un «homo summae frugalitatis», hecho a sí mismo gracias a su singular «quaerendi et custodiendi scientia» (101.2.4), es decir, a su capacidad para conseguir tanto como conservar. Un ejemplo claro de la provincialis parsimonia que caracterizaba, más allá del tópico literario, a los homines novi de provincias. Añade sobre él que «mari et terra pecuniam agitabat» (101.4.1), es decir, que participaba en negocios lucrativos, actividad que añadía al desempeño de cargos administrativos y al arrendamiento de vectigalia públicos como base fundamental de su fortuna ${ }^{21}$. Si en verdad Cornelio Senecio cimentó su fortuna tanto sobre la gestión de los publica vectigalia, como sobre los cargos y los negocios marinos y terrestres, se infiere que hubo una relación directa con los recursos económicos que se dedicaban a estas actividades, relación clara a los ojos de Séneca, quien los desgrana uno tras otro.

Si bien debemos tomar la conexión entre los Anii Seneciones de Carteia de mediados del siglo i d. C. y el Cornelius Senecio Annianus de la misma ciudad, cónsul en 146, a través del caballero de época neroniana Cornelius Senecio amigo de Séneca como una mera hipótesis, en caso de verificarse, permitiría arrojar información acerca de la ascensión social de familias de origen provincial cuyos miembros vemos incluidos sucesivamente en los ordines ecuestre y senatorial.

Respecto al segundo caso, aquellos personajes que ya partían de una situación social privilegiada, puede resultar paradigmático el anteriormente citado C. Aemilius Niger Annius Senecae f. Arvacus, de Sexi, flamen provincial de la segunda mitad del siglo II $d$. C. cuyo padre natural habría sido un Annius Seneca. Con este último nombre conocemos a un individuo que fue duovir en Ilurco en época de Marco

\footnotetext{
${ }^{21}$ Entre los negotia ubicados en tierra pudo contarse la gestión de minas de oro u otros metales. Los publica a que se refiere Séneca no pueden ser más que aquellos contratos estatales a partir de los cuales... «uectigal fiscus capit; quale est uectigal portus, uel uenalium rem, item salinarum et metallorum et picariarum» (Digesto 50.16.17).
} 
Aurelio y Cómodo (CIL II, 5511, CILA IV, 74), por lo que parece probable no sólo una relación familiar entre ellos, sino una comunión de intereses entre los Aemilii, los Annii y los Cornelii que no puede ser soslayada. De hecho, vemos cómo las relaciones familiares describen un complejo entramado: el Annius Seneca de Ilurco desempeñó el duovirato hacia 165 o 166 d. C. junto a un colega llamado Q. Cornelius Macro, de la misma gens, por tanto que Q. Cornelius Senecio Annianus de Carteia, cónsul sufecto de 146 d. C., el cual (tal vez no sea un dato baladí), ocupó en su ciudad de origen el mismo sacerdocio, el de Hércules, que desempeñó un tal Annius Rufus, hermano de un Annius Senecio, de Graena (Granada: H.Ep 2, 1990; n. $\left.{ }^{\circ} 403\right)$.

Puede pensarse que las conexiones familiares citadas son fruto de una mera casualidad, derivada de la frecuencia atestada de estos nomina en la provincia, pero la pervivencia en alguno de estos individuos de un sustrato indígena presente en los nombres Arvacus o Annius y su relación con familias ilustres como la de los Cornelii y los Aemilii parece ponernos tras la pista de las formas de integración de los provinciales de origen local en las elites imperiales y de su ulterior ascensión en la pirámide social.

De hecho, resulta significativa la constatación tardía (222 d. C) del nombre Annius entre los componentes de un poliónimo documentado en una inscripción de Ulia (CIL II, 1533), cuyos segundos tria nomina, aunque muy deteriorados, permiten identificar claramente el registro del personaje dedicante, Q. Fabio Fabiano. Si la restitución es, como parece, correcta (Lacort et alii 1986, 90-92), tendríamos a un miembro de la elite provincial -Q. Fabius Fabianus ...iato...Annius...erus-, seguramente patrono de la ciudad, erigiendo en nombre de la propia ciudad una dedicatoria a Severo Alejandro en el año del duovirato de L. Aelius Optatus y T. Clodius Tr..eti en Ulia. Los mismos nombres se repiten en una dedicatoria a Iulia Mammea de la misma procedencia y el mismo año que la anterior (Lacort et alii 1986, 92-93).

La mención de un Fabius Fabianus en la inscripción de Ulia no carece de interés en este contexto. El nomen Fabius resulta nuevamente uno de los más extendidos en la epigrafía hispana, pero en el caso de los Fabii Fabiani estamos con seguridad, como en su día demostró A. Canto (1978), ante una de las familias béticas de mayor brillo social durante el Alto Imperio. Las inscripciones que la mencionan se fechan en su mayoría en los siglo II y III d. C. y proceden sobre todo de localidades enclavadas en el entorno de las serranías penibéticas. Sólo las inscripciones de Monesterio (Badajoz), Luque (Córdoba) y Sevi- 1la (Canto 1978 295-296) se alejan de esta área comprendida entre los ríos Guadiaro y Vélez, en la actual provincia de Málaga. El Fabius Fabianus de Sevilla, no obstante, deja constancia de su origo ilurconenese y puede considerarse, por tanto, como procedente del núcleo geográfico de dispersión de los testimonios acerca de esta rama de los Fabii.

G. Chic García ha puesto de manifiesto recientemente la relación de los Fabii Fabiani y los Fabii Iuliani con la producción y el comercio para la $A n$ nona del aceite bético, gracias al testimonio de los tituli y de las marcas de alfar sobre ánforas olearias béticas del tipo Dressel 20 (Chic 2003). Dicha relación puede seguirse de nuevo en la inscripción de Ulia, en la que uno de los duumviri que la datan se llamó L. Aelius Optatus, justamente el mismo nombre del mercator o diffusor al que pertenecen varios tituli picti del Testaccio con al menos una datación consular en 154 d.C. Así pues, difícilmente pudiera tratarse del mismo Aelius Optatus de Ulia (Montemayor), ya que estas inscripciones se fechan en 222, casi cincuenta años más tarde, pero sí de un probable familiar de éste.

Por otra parte, continuando con esta enumeración de intereses familiares, la documentación sobre los Aelii resulta abrumadora; una Aelia Optata se documenta en Nescania (CIL II, 54902), con motivo de la erección de una estatua a su hijo L. Aelius Mela, acto acompañado de un epulum público. Otro Aelius Fabianus aparece como diffusor de aceite bético en 160 d. C. (Chic García 1988, p. 5) y, hacia fines del siglo II o principos del III d. C., se documenta un Aelius Aelianus en un ánfora salsaria del tipo Beltrán IIBAugst 30 procedente de Lora del Río (Remesal Rodríguez 2002, 212, ${ }^{\circ} 50$ ). Con el mismo nombre del negotians salsarius de Lora aparece un productor de aceite en un ánfora de $145 \mathrm{~d}$. C. del Testaccio (CIL $\mathrm{XV}, 4049$ ) comercializada por el diffusor $\mathrm{Q}$. Vinisius Serenus. Tal vez se trate del L. Aelius Aelianus, duovir de Naeva, que donó todas las estatuas de un pórtico y ofreció a municipes et incolae un epulum con motivo del acontecimiento ( $A E$ 1958, 39; Del Hoyo Calleja 1989, 83). Igualmente como productora de aceite se muestra Aelia Aeliana cuyo producto transportó L. Antonius Epaphroditus (Chic García 1988, 8); otro L. Aelius Aelianus se presenta como diffusor olei, asociado a los Aelii Optatus, Caesianus y Lupatus en 154 , lo que de nuevo nos lleva a los Aelii Optati (Chic García 1988, 4).

Entre los personajes de algún modo relacionados con estos Aelii Béticos pudo contarse L. Lollius Aelianus de Singilia Barba, en la depresión de Antequera, cuya hija Lollia Marciana casó como se ha 
señalado al principio de este trabajo, con el liberto L. Iunius Nothus Corn[elianus?], lo que permite encajar toda una serie de piezas en este aparente trabalenguas.

Así pues, a modo de balance, puede observarse la preeminencia económica progresiva de unas cuantas familias ligadas entre sí de variadas formas, así como a negocios remuneradores relacionados con el comercio y al abastecimiento del Estado. Estas familias procederían en parte de las aristocracias locales, caso de los Anni Senecae de Ilurco, que habían accedido a la ciudadanía romana gracias a sus relaciones clientelares con importantes personajes de los ordines superiores. En otras ocasiones, seguramente en pocas, se trataría de familias de libres más modestos, enriquecidos gracias a los negotia y con descendientes promocionados mediante mecanismos similares de ascenso social, caso de los Anni Seneciones de Carteia. Todos ellos, como es lógico, habrían tenido finalmente sus bases económicas en la posesión de tierras (incluyendo minas). Los primeros, respaldados por sus propiedades inmobiliarias habrían podido hacer inversiones remuneradoras en el ámbito comercial, incluyendo el transporte de bienes propiedad del Estado; los segundos, habrían alcanzado el estatus de possessores gracias a la compra de propiedades tras el éxito comercial, lo que no significa necesariamente un abandono efectivo del ámbito de los negocios. Todo ello dibuja un complejo panorama que conviene desenmarañar.

\section{LAS ELITES BÉTICAS Y SUS NEGOTIA. UN MUNDO COMPLEJO}

Una vez analizados los negotia y los publica de todo tipo que incrementaron la renta agrícola y, con ella, la fortuna de las gentes dominantes en la vida política y social de las ciudades béticas, quedan por determinar aún dos elementos fundamentales. Por una parte, debe analizarse de qué manera podían gestionar estos personajes su intrincada actividad económica en el contexto sociopolítico de la época; por otra parte, debe establecerse qué papel pueden haber desempeñado en sus negotia la producción y/o el comercio de salazones.

Muchas de éstas familias dominantes se remontarían a los años finales de la República (Dardaine $200127)$ y habrían logrado un ascenso fulgurante a lo largo del siglo I d. C. gracias, entre otros, a los negocios marítimos. Dicho ascenso fue, en no pocas ocasiones, incluso anterior a la promoción municipal de sus ciudades de origen. Este debió ser el caso de D. Iunius Melinus de Cártama, en Málaga, que fue eques Romanus ex ciuitate Cartimitana primus factus (CIL II, 1955), inscripción en la que el término ciuitas indica un momento previo a la municipalización. Entre sus sucesores estuvo Iunia Rustica, sacerdotisa perpetua et prima in municipio Cartimitano, casada a su vez, ¿pura casualidad?, con un C. Fabius Fabianus y madre de un C. Fabius Iunianus, quien aparece asociado a ella en actos de evergesía ciudadana en su localidad de origen (CIL II, 1956). Un Decimus Iunius R... y varios Fabii se encuentran implicados en el tráfico del aceite bético para la Annona, mientras que no faltan los Iunii, entre ellos el Puteolanus de Suel, actuando como mercatores de la salazón bética entre la segunda mitad del siglo I y la primera del ir d. C. (Chic García 1996, 21) .

No carece de interés el que Iunia Rustica de Cartima indique, entre otros actos evergéticos, la asunción por su parte de los publica uectigalia, lo que liberaba a su ciudad del peligro de endeudarse en exceso. En estos momentos de fines del siglo I dC. o principios del siglo II d. C., la conductio vectigalium no fue tal vez tan remuneradora como en los de los últimos Julio-Claudios, en que veíamos el ejercicio de los publica como una de las causas de la fortuna del caballero Cornelius Senecio, pero la capacidad de Iunia Rustica para vindicarlos, así como las conexiones de su familia con la exportación del aceite, salazones y probablemente mármol malagueños (Canto 1978) evidencia una clase local de terratenientes y prestamistas que consideraron la explotación económica de las comarcas que controlaban como una forma rápida de acumular la riqueza necesaria para aumentar su ascendiente político y social.

Es seguramente esta aristocracia provincial la que, en casos como el de los Cornelii, los Annii o los Fabii, supo trascender los límites de su mundo de origen y alcanzar los más altos escalones de la carrera senatorial. Asimismo, puede inferirse que dichas familias se encuentran tras los libertos que ejercían directamente los negocios comerciales, así como tras las operaciones financieras que enlazaban ámbitos de actividad en principio tan diferentes como la pesca, la producción de sal, la de salazones y la de envases para su distribución, en una especie de producción económica complementaria (Martínez Maganto 1992). Muchas de estas actividades podrían llevarse a cabo sobre la base simplemente de los dominios agrícolas que terratenientes como los Cornelii Pusiones poseían en la bahía de Cádiz (Chic García 2004, 95-96) o como los que los Fabii y Iuniii poseían en la costa mediterránea. Los ingresos generados por la producción de salazones, de ánforas o de 
sal en los propios predios debió complementarse con la adquisición de inmuebles o tierras de albina propiedad del Estado o del municipio, pues sabemos que las dos condiciones que cualificaban para el acceso a los arrendamientos públicos eran tener solidez económica, es decir tierras, y buenas relaciones con los miembros del ordo municipal, de quienes dependían las locationes (Rodríguez Neila 1994, 441).

Es probable que los vectigales derivados de los arriendos públicos se pagasen, al menos parcialmente, en especie y tuviesen por destino horrea de titularidad municipal que podían ser, ellos mismos objeto de locación, como en el caso de Puteoli, (Tabula Pompeiana Sulpiciorum 51: Virlouet 2000, 135) ${ }^{22}$. Pero no es menos probable que, en su papel de conductores de bienes municipales entre ellos salinas y factorías de salazón, las grandes fortunas de las ciudades actuasen realquilando a terceros los arriendos hechos a la ciudad, como en el caso del pompeyano Caecilius Iucundus, que refiere una fullonica, los vectigales de los pastos públicos (pascua), las tasas sobre las ventas (mercatus) y un fundus propiedad de la colonia (Andreau 1974), lo que recuerda muy de cerca la situación de los conductores pascua, salinarum, picariorum et commerciorum.

Entre estos últimos podían y debían contarse, como fue el caso de Aulus Umbricus Scaurus de Pompeya, un amplio abanico de clientes y dependientes que configuraban algo así como una familia in negotiis o negotians (Étienne; Mayet 2001, 94) y que actuaban como agentes, intermediarios y/o testaferros en los negocios industriales y las empresas comerciales de sus domini.

Un nuevo testimonio, en este caso asociado al negocio de mármoles, abunda en esta idea. Una inscripción de Nescania (CIL II, 2011), en la comarca de Antequera, recoge la dedicación de una estatua a C. Marius Clemens por parte de su madre Fabia Restituta, con la consiguiente celebración de un banquete acompañado de una donación de sportulae en denarios a los decuriones, sus hijos, los ciudadanos y los incolae del municipio, así como la donación de diez denarios a unos misteriosos servi stationarii. A. M. Canto (1978, 306) relacionó en su día a estos stationarii con los esclavos vinculados de algún modo con una cantera y taller de mármoles, propuesta que debe ser aceptada a la luz de la inscripción del negotians marmorarius Aurelius Xenonianus Aquila (SEG IV, 106; Pa-

\footnotetext{
${ }^{22}$ Los almacenes subterráneos de urbes salineras tan importantes como Arlés y Narbona (Alzon 1965, 329) suelen citarse a propósito de un texto de Vitrubio (5.9.8) en el que refiere el uso de criptopórticos como almacenes de sal y trigo tanto de los municipios como de los privados.
}

dilla Monge 2000, 233), quien gestionaba en Roma una statio marmoraria. La ubicación de la statio de Aquila, no en la cantera, sino en los horrea Petroniana de Roma serviría de argumento para sugerir que los stationarii de Nescania podían hallarse relacionados no con la cantera en sí, sino más bien con un almacén ( ¿de titularidad pública?) en el que pueden haber actuado como mercatores o como artesanos de productos marmóreos. O ambas cosas.

Pero lo que resultaría más importante en este contexto sería la posible relación de un notable local, a través de servi interpuestos, con la explotación y gestión de bienes del dominio público, como las canteras, modelo que reproduciría a escala local el funcionamiento de las canteras imperiales gestionadas mediante libres y libertos del emperador, actuando en calidad de conductores (Padilla Monge 2000; 2002). Desde luego, cabe la posibilidad de que la statio Nescaniensis fuera de propiedad privada, pero esto no cambiaría necesariamente las cosas, porque sabemos que los privados solían añadir a la gestión de su patrimonio el arrendamiento de publica afectos a la misma actividad, ya que, como se ha señalado «publicanorum loco sunt» (Digesto 39.4.13). Igualmente interesante es la afirmación de que estos conductores, que actuaban en calidad de publicanos, se encontraban encargados fundamentalmente de los vectigalia derivados de las tasas portuarias, los impuestos sobre las ventas, las salinas, las minas -en el número de las cuales se contaban las canteras-, y las pegueras (Digesto 50.16.17).

A tenor de los datos hasta ahora expuestos podemos inferir que, desde un momento indeterminado a partir de época julio-claudia tardía o flavia, las grandes familias de la Bética fueron acaparando a través de dependientes, libres o esclavos, el control de las actividades productivas (y comerciales) ligadas a la gestión de bienes privados y públicos ubicados en sus áreas de influencia, entre los que se contaron sin duda los saladeros y las salinas. Este hecho fue paralelo $\mathrm{y}$, en cierto sentido, solidario con otros dos fenómenos que pueden deducirse entre líneas en muchas de las inscripciones que se han analizado en estas páginas: la creciente importancia que fue adquiriendo la producción y la distribución de aceite provincial frente a las salazones y los metales; y la progresiva implicación de las aristocracias béticas en actividades evergéticas de tipo alimentario que a partir del siglo II d.C. acompañaron a las dedicaciones de estatuas, edificios o juegos, o las sustituyeron.

Es bien sabido que la colaboración con la Annona estatal permitió a navicularii y negotiatores huir de las liturgias municipales que pesaban sobre las 
espaldas de los curiales sucediéndose una progresiva dedicación de los collegia de estos agentes económicos a la Annona; el caso de Arlès resulta paradigmático en este sentido (CIL III, 14165 y 14168). Ello puso a muchas de las familias béticas enriquecidas a lo largo del siglo I d. C. en disposición de invertir parte de sus ganancias en las compañías navieras y de reorientar sus inversiones agrarias hacia el olivo, una planta cuyo cultivo se incentivaba claramente gracias a las compras estatales de aceite, fomentando una bien conocida correlación entre las actividades de la agricultura y las del comercio (D’Arms 1981, 158 y ss.). Con ánimo de diversificar los riesgos y ganancias, estas familias fueron optando por ampliar sus inversiones desviándolas hacia otras materias alimenticias, bien aprovechando la concurrencia comercial junto al aceite o por el propio interés del Estado en estos productos, que eran necesarios para el abastecimiento de ciertas áreas, especialmente las militarizadas, como ocurrió con el caso de las salazones que abastecían el limes germano o Britannia, como ponen de manifiesto los numerosos testimonios de epigrafía anfórica.

Sin duda, las necesidades del Estado beneficiaron a los aristócratas béticos y a sus dependientes tanto como perjudicaron a sus ciudades de origen. Mientras los primeros acumulaban en sus manos la propiedad o la gestión de las tierras, las salinas, las canteras y los bosques provinciales, las ciudades perdían el ingreso que tradicionalmente les habían proporcionado las sumas honorarias y las liturgias de sus magistrados más poderosos. Debe considerarse, no obstante, que las evergesías y las donaciones, siempre voluntarias, pudieron suplir durante algún tiempo la ausencia de ingresos procedentes de los honores debidos por los magistrados entrantes. Sin embargo, cuando las dificultades económicas se hicieron sentir en las finanzas de las ciudades y en la solidez financiera de sus curiales, las evergesías y las fundaciones alimentarias debieron venir a complementar a las monumentales, en un primer momento, para paulatinamente suplirlas.

Por entonces, el Estado había ampliado las ventajas ofrecidas a los navicularii al tiempo que los apuros económicos del físco comenzaban a dificultar los pagos regulares de las vecturae o compensaciones monetarias a los navicularii por los transportes (Chic García 1999). El testimonio del jurista Gayo permite concretar que el Estado, hacia este momento, concedió el derecho de corpus habere a los corpora de navicularii, lo que sin duda supuso una ventaja a la par que un inconveniente para éstos, ya que a cambio de ciertos derechos se aumentaba el con- trol estatal sobre estas corporaciones. Precisamente, la posición ya mencionada de Athenio con respecto al prefecto de la Annona o la de Aemilius Niger con respecto al flaminado provincial, sólo se entienden en un ambiente general en el que el Estado y los miembros de las corporaciones de negotiantes y navicularii se necesitaban mutuamente en una simbiosis que perjudicaba a las ciudades de origen, de las que éstos se ausentaban incluso físicamente, ya sea para servir a sus propios intereses económicos o para entrar en el círculo imperial como altos oficiales de la administración estatal.

Para evitar lecturas erróneas, conviene advertir que ni las salazones ni otras mercancías libres formaban parte de los productos estrictamente annonarios durante el Alto Imperio Romano. Sin embargo, como ha señalado P. Herz (1988, 72-73), cualquier bien en cualquier lugar del Imperio podía ser eventual objeto del interés del Estado, en cuanto a su compra y transporte, para garantizar la satisfacción de las necesidades oficiales a que hubiere lugar. Por tanto, en este sentido, parece obvio que la cercanía de los negotiantes salsarii o vinarii a los oficiales de la oficina de abastecimientos resultaría provechosa tanto para los comerciantes, quienes se aseguraban la contratación de los aprovisionamientos necesarios, como para la propia Annona estatal, que cubría necesidades puntuales, como el abastecimiento a los campamentos militares. La Annona a su vez, tendría garantizada la disponibilidad de los medios de transporte adecuados al mantener lazos especiales de colaboración con determinados collegia de comerciantes.

Un escalón por debajo de los grandes negociantes bien relacionado con las instancias estatales debió estar el estrato de los comerciantes y salsarii libertos que, como nuestro Puteolanus de Suel, no trabajaban directamente para sus patrones de mejor posición social como solía ser la norma (López Barja 1991), sino que se apoyaban en los colegios de sevires y en las corporaciones profesionales locales. Estos personajes debieron cumplir, con respecto a las diversas annonae ciudadanas, una función similar a la de las corporaciones profesionales con respecto a la administración annonaria del Estado. El caso de L. Iunius Nothus de Singilia Barba resulta ilustrativo para comprender cómo los recursos económicos de los comerciantes de escaso brillo social ayudaron a los curiales y a las ciudades en apuros a mantenerse a flote económicamente, a la vez que garantizaban el abastecimiento de géneros comerciales, entre ellos probablemente el garum. Así pues, entre los profesionales de menor nivel y los quinquennales de las 
corporaciones más poderosas debieron establecerse relaciones de patrocinio, como ilustra la relación de los Clodii malagueños con las corporaciones de mercatores orientales presentes en la ciudad. De este modo, al control creciente de los corpora negotiantium por parte del Estado central debió añadirse relativamente pronto una rígida estructuración jerárquica que afectaba a todos los estratos de la organización comercial, gracias a los mecanismos propios del patronazgo y la clientela.

El panorama que dibujan las diferentes situaciones socio-económicas aludidas en las páginas anteriores, podrían resumirse en una rápida y escueta visión diacrónica que permita sintetizar tan compleja evolución: al mundo comercial fragmentado, variado y vigoroso del primer siglo de nuestra Era, reflejado en las compañías de salsarii de mayor o menor entidad económica que muestran los tituli sobre ánforas salsarias, debió sucederle un sistema más estatalizado y esclerotizado. En este nuevo marco, unas cuantas familias, enriquecidas gracias al antiguo sistema menos restrictivo, terminaron por ejercer el control sobre los recursos productivos y comerciales de unas ciudades de cuyos intereses se fueron progresivamente distanciando para acercase a la administración central. Cuando ésta comience a sentir los primeros apuros financieros, la situación se hará poco a poco insostenible para las ciudades, lo que conllevará al progresivo colapso del sistema. Los beneficios obtenidos por parte de las ciudades a través de los mecanismos evergéticos se fueron diluyendo a medida que los intereses de los comerciantes locales se desplazaron hacia el centro de poder del Estado, erosionando de forma irreversible la capacidad de gestión económica por parte de los poderes locales.

Así pues, a modo de resumen, en estas páginas se han esbozado varios modelos de comportamiento socioeconómico que podrían arrojar luz sobre los mecanismos y procesos de promoción social de comerciantes y negotiatores relacionados con el mundo de las salazones. Es evidente que aquí no se pretende establecer criterios rígidos y exhaustivos para definir estas situaciones, ya que, quizá rastreando nuevas evidencias provenientes de la epigrafía lapidaria y estableciendo conexiones con el creciente número de epígrafes anfóricos así como con otros sectores de la actividad económica (minas, bosques, canteras de mármol...), podamos dibujar en un futuro cercano un panorama global más exacto de los mecanismos de promoción social que experimentaron estas especializadas gentes del comercio en la Bética romana, sin duda una de las más destacadas y genuinas áreas de producción y comercia- lización de salazones, especialmente durante el Alto Imperio.

\section{BIBLIOGRAFÍA}

Alzon, C. 1965: Problèmes relatifs à la location des entrepôts en droit romain. Paris.

Andreau, J. 1974: Les affaires de monsieur Iucundus. Roma.

Arata, F.P. 1994: «Un relitto da Cala Rossano (Ventotene)» Collection École Française de Rome 193; 477-496. Roma.

Aubert, J. J. 1994: Business managers in Ancient Rome: a social and economic study of institores, $200 B C-A D$ 250. Leiden.

Berni, P. 2008: Epigrafía anfórica de la Bética. Nuevas formas de Análisis. Col-lecció Instrumenta $n^{\circ}$ 29. Barcelona.

Berti, F. 1990: Fortuna Maris. La nave romana di Comachio. Bologna.

Biscardi, A. 1982: «Introduction à l'étude des pratiques commerciales dans 1'histoire des droits de l'Antiquité». Rev. Int. des droits de l'Antiquité, $3^{\text {a }}$ Ser., 29, 21-44, Bruxelles.

Blänsdorf, J. Von. 1985: «Drei Mainzer amphoreninschriften». Archäologisches Korrespondenzblatt 15; 91-93. Wiesbaden.

Caballos, A. 1990: Los Senadores Hispanorromanos y la Romanización de Hispania (Siglos I-III). I: Prosopografía 2 vols. Écija.

Camodeca, G. 1999: Tabulae Pompeianae Sulpiciorum. Edizione critica dell'archivio puteolano dei Sulpici. Roma.

Canto, A. 1978: «Una familia bética: los Fabii Fabiani». Habis 9; 293-310. Sevilla.

Carreras, C. 1997: «Los beneficiarii y la red de aprovisionamiento militar de Britannia e Hispania». Gerion 15; 151-176. Madrid.

Carreras, C. 2006: «Transition of the military supply from the Late Republic to Augustan period: a case study of the NW of the Iberian Peninsula». En Naco, T. y Arrayás, I. Guerra y Territorio en el mundo romano (B.A.R.I.S., 1530). London.

Castillo García, C. 1982: «Los senadores béticos. Relaciones familiares y sociales», en Epigrafia e ordine senatorio II; 465-519. Roma.

Castillo García, C. 1983: «Los senadores de la Bética. Onomástica y parentesco». Gerión 2; 239 250. Madrid.

Chic García, G. 1983: «El estado y el comercio aceitero durante el alto Imperio». En Blázquez Martínez, J. M.; Remesal Rodríguez, J., Segundo Con- 
greso Internacional sobre Producción y Comercio del aceite en la Antigüedad; 163-191. Madrid.

Chic García, G. 1988: Epigrafía anfórica de la Bética II. Consideraciones sobre la annona. Écija.

Chic García, G. 1993: «Los Aelii en la producción y difusión del aceite bético». Münsterische Beiträge Zur Antiken Handelsgeschichte 11.2; 1-22. Münster.

Chic García, G. 1996: «Producción y comercio en la zona costera de Málaga en el mundo romano en época altoimperial». En Wulff, F y Cruz, G. (Eds.): Historia Antigua de Málaga y su Provincia; 245-266. Málaga.

Chic García, G. 1999: «Algunas notas sobre Alejandro Severo y el fisco». En Alonso, A. (Coord.): Homenaje al profesor Montenegro: Estudios de Historia Antigua; 649-658. Valladolid.

Chic García, G. 2003: «Nuevos datos económicos sobre el senador hispalense Fabius Iulianus». Vrbs Aeterna. Coloquio Internacional Roma entre la Literatura y la Historia; 381-396. Pamplona.

Chic García, G. 2004: «La ordenación territorial en la Bahía de Cádiz durante el Alto Imperio Romano». Gadir-Gades. Nueva Perspectiva Interdisciplinar; 75-105. Sevilla.

Chic García, G. 2005: «Marco Aurelio y Cómodo. El hundimiento de un sistema económico». II Congreso Internacional de Historia Antigua. La Hispania de los Antoninos (98-180); 567-586. Valladolid.

Chic García, G. 2008: «Una perspectiva de la economía en el sur de Hispania durante la República romana», en J. Uroz, J. M. Noguera; F. Coarelli (eds.): Iberia e Italia. Modelos romanos de integración territorial, Actas del IV Congreso Hispano-Italiano Histórico-Arqueológico, Murcia, 325352.

Chic García, G. (2009): El comercio y el Mediterráneo antiguo. Madrid.

Chic García, G.; García Vargas, E.; Romo Salas, A. S.; Tabales Rodríguez, M. A. 2001: «Una nueva inscripción annonaria de Sevilla: $M$. Iulius Hermesianus, diffusor olei ad annonam Urbis». $\mathrm{Ha}$ bis 32; 353-374. Sevilla.

Colls, D.; Étienne, R.; Liou, B.; Mayet, F. 1977: «L'épave Port-Vendres II et le commerce de la Bétique à l'époque de Claude». Archeonautica, 1 (Número monográfico). Paris.

Curtis, R.I. 1979: «The Garum Shop of Pompei». Cronache Pompeiane 5; 5-23. Napoli.

Curtis, R.I. 1984: «The salted fish industry of Pompeii!». Archaeology 37-6; 58-59 y 74-75. N.York.
Curtis, R.I. 1988: «A.Umbricus Scaurus of Pompeii». Studia Pompeiana \& Classica in Honor of W.F. Jashemski, I; 19-49. N.York.

D'arms, J. H. 1981: Commerce and social standing in ancient Rome. Cambridge.

Dardaine, S. 2001: «La naissance des elites hispanoromaines en Bétique». En Navarro, M. y Demouguin, S. (eds.): Élites hispaniques 23-44. Bourdeaux.

Del Hoyo Calleja, J. 1989 «Nuevas lecturas de epigrafía hispana». Espacio, Tiempo y Forma, Serie II, $H^{a}$ Antigua, t. II, 1989; 81-94. Madrid.

Desbat, A. 1991 : «Un bouchon de bois du premier s. après J.-C. recueilli dans la Saône à Lyon et la question du tonneau à l'époque romaine». Gallia 48, 319-336.

Desbat, A.; Lequément, R.; Liou, B. 1987: «Inscriptions peintes sur amphores: Lyon et Saint-Romainen Gal». Archaeonautica 7; 141-166. Paris.

Domergue, C. 2007: «Retour sur les lingots de plomb de Comacchio (Ferrara, Italie) en passant par l'archéométrie et l'épigraphie». [Consultar on line en la dirección del recurso «arXiv» en el enlace http:/ /arxiv.org/ftp/physics/papers/0605/0605044. pdf.].

Ehmig, U. 1995: «Allex oder Anderes». Mainzer Archäol. Zeitschrift 2; 117-130. Mainz.

Ehmig, U. 1996: «Garum für den Statthalter. Eine Saucenamphore mit Besitzeraufschrift aus Mainz». Mainzer Archäol. Zeitschr 3; 25-56. Mainz.

Ehmig, U. 2003: «Die römische Amphoren aus Mainz, Frankfurt.

Ehmig, U.; Liou, B.; Long, L. 2004: «Le garum de Caius Saturius Secundus, gouverneur de la province romaine de Rétie ».R.E.A. 106 ; 123-132. Paris.

Étienne, R. 1970: «A propos du garum sociorum». Latomus XXIX; 297-313. Bruxelles.

Étienne, R.; Mayet, F. 1993-1994: «La place de la Lusitanie dans le commerce méditerranéen», Conimbriga 32-33; 201-218. Coimbra.

Étienne, R.; Mayet, F. 1998: «Les mercatores de saumure hispanique». Mélanges de l'école Français de Rome 110-1; 147-165. Paris.

Étienne, R.; Mayet, F. 2001: «Les élites marchandes de la península Ibérique». En Navarro, M. y Demouguin, S. (Eds.): Élites hispaniques; 90-99. Bourdeaux.

Étienne, R.; Mayet, F. 2002: Salaissons e sauces de poisson hispaniques. Paris.

Éveillard, J.Y. (2008) : «A propos de la découverte d'une statue de Neptune à Douarnenez (Finistère): «Caius Varenius Varus, producteur de salaisons de poissons». En Napoli, J. 2008 : <Ressources et activités maritimes des peuples de l'Antiquité, 
Actes du Colloque International de Boulogne-surMer 12, 13 et 14 Mai 2005. Les Cahiers du littoral 2, 6; 395-400. Boulogne-sur-Mer.

García-Bellido, M. P. 1986: «Nuevos documentos sobre minería y agricultura romanas en Hispania», AEspA 59; 3-46. Madrid.

García-Bellido, M. P. 1998: «Sellos legionarios en los lingotes de plomo de Comacchio», Epigraphica 60, 9-43. Bologna.

García Brosa, G. 1999: «Mercatores y negotiatores: ¿Simples comerciantes?» Pyrenae 30; 173-190. Barcelona.

García Vargas, E. 1998: La producción de ánforas en la bahía de Cádiz en época romana (siglos II a. c.-IV d. c.). Écija.

García Vargas, E. 2007: «Hispalis como centro de consumo desde época tardorrepublicana hasta la Antiguiedad Tardía. El testimonio de las ánforas». Anales de Arqueología Cordobesa 18; 317-360. Córdoba.

García Vargas, E.; Martínez Maganto, J. 2006: «La Sal de la Bética romana. Algunas cuestiones sobre su explotación y comercio», Habis 37; 253274. Sevilla.

Gofas, D. C. 1993: «Encore une fois sur la Tabula Pompeiana 13 (Essai d'une intérpretation nouvelle)». Symposion; 251-266. Koeln.

Haley, E. W. 1988: «Roman elite involvement in commerce: The case of the Spanish TT.Mamilii». AEspA 61; 141-156, Madrid.

Haley, E. W. 1990: «The Fish sauce trader L. Iunius Puteolanus». Zeitschrift Papyrologie und Epigraphik 80; 72-78; Bonn.

Herz, P. 1988: «Der praefectus annonae und die Wirschaft des westlichen Provinzen». Ktema 13; 69-85. Strasbourg.

Lacort, P.; Portillo, R.; Stylow, A. 1986: «Nuevas inscripciones latinas de Córdoba y su provincia». Faventia 8/1; 69-109. Barcelona.

Lagóstena, L. 2001: La producción de salsas y conservas de pescado en la Hispania Romana (II aCVI dC) Col-lecció Instrumenta $n^{\circ} 11$. Barcelona.

Lagóstena, L. 2002-3: «Aportación al conocimiento de la sociedad de la costa de la Ulterior en época republicana y Julio-Claudia. El registro $\delta$ en los tituli picti de las ánforas salsarias de Castra Praetoria» Lucentum 2002/3; 227/236. Alicante

Lagóstena, L. 2004: «Las ánforas salarias de Baetica. Consideraciones sobre sus elementos epigráficos». En Remesal, J. (Ed.): Epigrafía anfórica Col·lecció Instrumenta $n^{\circ}$ 17. 197-220. Barcelona.

Laubenheimer, F; Martínez Maganto, J.; Hillairet, JL. 1993: «Inscription sur une amphore à thon de
Bétique, Saintes, Charente-Maritime». Aquitania 11. 243-254. Bourdeaux.

Leveau, P. (Dir.) 1985: Origine des richesses dépensées dans la ville antique (Actes du Colloque, Aix en Provence 1984). Aix-En-Provence.

López Barja, P. 1991: «La dependencia económica de los libertos en el Alto Imperio romano». Gerion 9; 163-174. Madrid.

Marlière, É. 2002: L'outre et le tonneau dans l'occident romain. Montagnac.

Martin-Kilcher, S. 1987: Die römischen Amphoren aus Augst und Kaiseraugst. Ein Beitrag zur römischen Handels und Kulturgeschichte. 1: Die südspanischen Ölamphoren. Forschungen in Augst 7/1. Augst.

Martin-Kilcher, S. 1990: «Fischsaucen und Fischconserven aus dem römischen Gallien». Archéologie Suisse 13, 37-44. Bâle.

Martin-Kilcher, S. 2002 : «Lucius Urittius Verecundus, négociant à la fin du Ier s., et sa marchandise découverte à Mayence». En Rivet, L; Sciallano, M (eds.), Vivre, produire et échanger: reflets méditerranéens. Mélanges offerts à Bernard Liou. 343-353. Montagnac.

Martínez Maganto, J. 1992: «Los sistemas de pesca en la Antigüedad y su implicación en el abastecimiento de las industrias de salazón». Cuad. Prehist. y Arq. U.A.M., 219-244. Madrid.

Martínez Maganto, J. 2000: «Inscripciones sobre ánforas de salazón: interpretación sobre la estructura y significación comercial de los tituli picti». Congreso Internacional Ex Baetica Amphorae, Vol. IV, 1207-1219. Sevilla

Martínez Maganto, J. 2005: «La sal en la Antigüedad: Aproximación a las técnicas de explotación y comercialización. Los Salsamenta» III Congreso Internacional de Estudios Históricos «El Mediterráneo el mar de la sal» (Santa Pola, Noviembre de 2004. Santa Pola.

Martínez Maganto, J.; García Vargas, E. (e.p.): «Sal, producción salina e industrias de salazón en la Antigüedad. Una relación hermética». Congreso de la S.E.H.A. sobre Explotación histórica de la Sal: Investigación y Puesta en Valor. (Diciembre 2006). Ciempozuelos.

Mateo, A. 2001: «Observaciones sobre el régimen jurídico de la minería en tierras públicas en época romana». Santiago de Compostela.

Melchor Gil, E. 2006: «Las propiedades rústicas de las élites hispano-romanas: un intento de aproximación a través de la documentación epigráfica». En Rodríguez Neila, J.F.; Melchor Gil, E. (eds.), Poder central y autonomía municipal: la proyec- 
ción pública de las élites romanas de Occidente; 241-280. Córdoba.

Menéndez Argüín, R. 2004: Las legiones romanas de Germania (s. II-III): Aspectos logísticos. Écija.

Millán León, J. 2001: «A propósito de la marca SOC y en torno al Garum Sociorum» Habis 31; 171184. Sevilla.

Morales Muñoz, C. 2005: «La relación entre el registro "Beta" de la epigrafía anfórica olearia bética y la onomástica de la inscripciones gaditanas altoimperiales». Gerión 23.1; 251-269. Sevilla.

Ordóñez Agulla, S. 1987-1988: «Cuestiones en torno a Singilia Barba». Habis 18-19; 319-344. Sevilla.

Ordóñez Agulla, S. 2005: «Inscripciones Procedentes de la Necrópolis de la Carretera de Carmona (Sevilla)». Romula 4; 245-274. Sevilla.

Padilla Monge, A. 2000: «Una aproximación a la Explotación y la distribución del Mármol en el Imperio Romano durante los Siglos I-II». Habis 31; 219-233. Sevilla

Padilla Monge, A. 2002: «Notas Sobre la Explotación de las Canteras Imperiales hasta el Reinado de Adriano. El Caso de Dokimeion». Habis 33; 433-446. Sevilla.

Parodi Álvarez, M. 2004: «Los MEVII: Una familia de productores, comerciantes y banqueros romanos en la Bética». Espacio y Tiempo, 163-175. Madrid.

Pavis D'escurac, H. 1977: «Aristocratie sénatoriale et profits commerciaux». Ktema 2; 339-355. Strasbourg.

Pavis D'escurac, H. 1988: «Origo et résidence dans le monde du commerce sous le Haut-Empire». Ktema 13; 57-68. Strasbourg.

Pérez Zurita, A. D. 2006: «Amici Hispanienses. Estudio epigráfico sobre las redes sociales de las élites hispanas». En Rodríguez Neila, J. F.; Melchor, E. (eds.), Poder central y autonomía municipal: la proyección pública de las élites romanas de Occidente; 313-358. Córdoba.

Remesal Rodríguez, J. 2002: «Parte superior de ánfora». En Comes, R.; Rodá, I. (eds.), Scripta manent. La memoria escrita dels romans / La memoria escrita de los romanos; 212. Barcelona.

Remesal Rodríguez, J. 2008: «Olearii». En Caldelli, M.; Gregori, L.; Orlandi, S. (eds.) Epigrafia 2006. Atti della XIVe rencontre sur l'épigraphie in Onore di Silovio Panciera con altri contributi di Colleghi, allievi e collaboratori. Tituli 9; 349-374. Roma.
Rodá, I. 2004: «Agripa y el comercio del Plomo». Mastia 3; 183-193. Cartagena.

Rodríguez Almeida, E. 1972: «Novedades de epigrafía anfórica del Monte Testaccio». Recherches dur les amphores romaines. Coll. École. Française de Rome 110; 107-211. Roma.

Rodríguez Almeida, E. 1974-1975: «Bolli anforari di Monte Testaccio», Boll. Comm. Arch. Com. Rom. 84; 199-248. Roma

Rodríguez Neila, J. F. 1994: «El epígrafe CIL, II, 2242 -Córdoba- y las locationes de propiedades públicas municipales». En González Román, C. (ed.): La sociedad de la Bética. Contribuciones para su estudio; 435-460. Granada.

Rovira Guardiola, R. 2007: «El archivo sulpicio y los tituli beta: circulación de comerciantes en el Mediterráneo». Acta XII Congressus Internationalis Epigraphiae Graecae et Latinae (Barcelona, 3-8 Septembris 2002). Monografies de la Secció Històrico-Arqueològica X. Barcelona; 1263-1268.

Serrano Delgado, J. M.; Luque Moraño, A.; Rodríguez Oliva, P. 1975: «Varia arqueológica malacitana». Jábega 11; 44-45. Málaga.

Stylow, A.; Gimeno Pascual, H. 2001: «Remissis cenis publicis. Las reglas del juego del evergetismo. A propósito de CIL II 1046 con un apéndice sobre CIL VIII 11058», Faventia 23/24; 97-109.

Valencia, M. 1989-90: «Mercator y Negotiator: Ambigüedad y realidad económica en la obra de Cicerón». Caesaraugusta 66/67; 195-216. Zaragoza.

Verboven, K. 2002: The Economy of Friends. Economic Aspect of Amicitia and Patronage in the Late Republic. Bruxelles.

Verboven, K. 2006: «Ce que negotiari et ses dérivés veulent dire». En Andreau, J.; Chankowski, V (eds.) Vocabulaire et expression de l'économie dans le monde antique. Études 19. L'économie antique. Bordeaux.

Verboben, K. 2007: «The associative order, status and ethos of Roman businessmen in Late Republic and Early Empire». Athenaeum; 861-893. Pavia. [Es posible acceder on line en http:// www.ancienthistory.ugent.be/history/en/ Verboven_working_paper_Negotiari.pdf ].

Virlouet, C. 2000: «Les denrées alimentaires dans les archives des Sulpicii de Pouzzoles», Cahiers Glotz. XI; 131-149. Paris.

Whittaker, D. 1985: «Trade and the aristocracy in the Roman empire». Opus 4; 49-75. Roma. 